\title{
Formation and Device Application of Ge Nanowire Heterostructures via Rapid Thermal Annealing
}

\author{
Jianshi Tang, ${ }^{1}$ Chiu-Yen Wang, ${ }^{2}$ Faxian Xiu, ${ }^{1,3}$ Yi Zhou, ${ }^{1}$ Lih-Juann Chen, ${ }^{2}$ and Kang L. Wang1 \\ ${ }^{1}$ Device Research Laboratory, Department of Electrical Engineering, University of California, Los Angeles, CA 90095, USA \\ ${ }^{2}$ Department of Materials Science and Engineering, National Tsing Hua University, Hsinchu 30013, Taiwan \\ ${ }^{3}$ Department of Electrical and Computer Engineering, Iowa State University, Ames, IA 50014, USA
}

Correspondence should be addressed to Kang L. Wang, wang@ee.ucla.edu

Received 21 April 2011; Accepted 14 June 2011

Academic Editor: Joseph Lai

Copyright (c) 2011 Jianshi Tang et al. This is an open access article distributed under the Creative Commons Attribution License, which permits unrestricted use, distribution, and reproduction in any medium, provided the original work is properly cited.

\begin{abstract}
We reviewed the formation of Ge nanowire heterostructure and its field-effect characteristics by a controlled reaction between a single-crystalline Ge nanowire and Ni contact pads using a facile rapid thermal annealing process. Scanning electron microscopy and transmission electron microscopy demonstrated a wide temperature range of $400 \sim 500^{\circ} \mathrm{C}$ to convert the Ge nanowire to a single-crystalline $\mathrm{Ni}_{2} \mathrm{Ge} / \mathrm{Ge} / \mathrm{Ni}_{2} \mathrm{Ge}$ nanowire heterostructure with atomically sharp interfaces. More importantly, we studied the effect of oxide confinement during the formation of nickel germanides in a Ge nanowire. In contrast to the formation of $\mathrm{Ni}_{2} \mathrm{Ge} / \mathrm{Ge} / \mathrm{Ni}_{2} \mathrm{Ge}$ nanowire heterostructures, a segment of high-quality epitaxial $\mathrm{NiGe}$ was formed between $\mathrm{Ni}_{2} \mathrm{Ge}$ with the confinement of $\mathrm{Al}_{2} \mathrm{O}_{3}$ during annealing. A twisted epitaxial growth mode was observed in both two Ge nanowire heterostructures to accommodate the large lattice mismatch in the $\mathrm{Ni}_{x} \mathrm{Ge} / \mathrm{Ge}$ interface. Moreover, we have demonstrated field-effect transistors using the nickel germanide regions as source/drain contacts to the Ge nanowire channel. Our Ge nanowire transistors have shown a high-performance $p$-type behavior with a high on/off ratio of $10^{5}$ and a field-effect hole mobility of $210 \mathrm{~cm}^{2} / \mathrm{Vs}$, which showed a significant improvement compared with that from unreacted Ge nanowire transistors.
\end{abstract}

\section{Introduction}

As an important one-dimensional material, semiconductor nanowire has attracted enormous research interest for its unique electrical properties, which has promising applications as building blocks for nanoelectronics [1-5]. Since 2004 , there have been a lot of efforts on studying the thermal diffusion of metal into a single-crystalline Si nanowire, in which a silicide/silicon/silicide nanowire heterostructure is formed by solid-state reactions between the Si nanowire and metal contacts. Many metals (contact pads or nanowires) have been studied as the diffusion source, such as Ni [6-8], Co [9], Pt [10], and Mn [11]. One of the salient features in this nanowire heterostructure is the atomically sharp interface between the Si nanowire and the formed silicide nanowire. Such clean interface may help to avoid Fermi-level pinning effect, which is commonly observed in conventional metal-semiconductor contacts [12]. Also, the nanowire heterostructure can be easily used to fabricate nanowire fieldeffect transistors (FETs) using the formed silicide regions as the source/drain contacts to the $\mathrm{Si}$ nanowire channel $[6,7,10]$. The channel length can be well controlled by the annealing time and growth length of silicide, therefore, can be aggressively shrunk down to sub-50 nm [11]. Clearly, this process offers great advantages over modern high-cost and complex photolithography technology to fabricate shortchannel transistors and may further facilitate the advance of scaled nanodevices.

Compared with Si nanowire, metal-Ge nanowire is a new system of interest, since Ge is an important complement to Si with even higher carrier mobilities for further device miniaturization compatible to the existing CMOS technology $[1,2]$. For Ge, the atomically sharp interface is of particular interest to alleviate the Fermi-level pinning effect in the metal-Ge contact, since Ge has a high density of interface states due to native defects on the Ge surface [12]. 
Experimentally, Yamane et al. have demonstrated the epitaxial growth of high-quality $\mathrm{Fe}_{3} \mathrm{Si}$ on $\mathrm{Ge}(111)$ substrate with an atomically controlled interface, which successfully depined the Fermi-level of $\mathrm{Fe}_{3} \mathrm{Si} / \mathrm{Ge}$ contact [19]. It is, therefore, highly desirable to achieve a metallic contact to Ge with a high-quality interface. On the other hand, many germanides, such as $\mathrm{Mn}_{5} \mathrm{Ge}_{3}$ and $\mathrm{Ni}_{3} \mathrm{Ge}$, exhibit ferromagnetism above room temperature $[20,21]$, and thus offer great advantages over silicides for future applications in spintronics, such as realizing spin injection into semiconductor from a ferromagnetic contact. Therefore, there is an increasing research interest on the metal-Ge nanowire system, such as Ni-Ge [13-15] and $\mathrm{Cu}-\mathrm{Ge}$ [16-18]. For comparison, Table 1 briefly summarizes the literature report of $\mathrm{Si}$ and $\mathrm{Ge}$ nanowire heterostructures formed by solid-state reactions between a semiconductor nanowire and metal contacts. It is noted that the annealing temperature of metal-Ge nanowire system is usually lower than that of metal-Si nanowire system, which is partially due to a lower melting point of Ge than Si. The low-temperature process in metal-Ge nanowire systems is favorable to reduce the thermal budget in forming nanowire heterostructures toward future process integration.

In this paper, we will first discuss the formation of singlecrystalline $\mathrm{Ge}$ nanowire heterostructure by the solid-state reaction between a Ge nanowire and $\mathrm{Ni}$ contact pads. By a comparative study of with or without an $\mathrm{Al}_{2} \mathrm{O}_{3}$ capping layer during annealing, we study the effect of oxide confinement in the growth of germanide in a Ge nanowire. A detailed transmission electron microscopy (TEM) analysis including the epitaxial relationships is presented in this section. In the second part of this paper, we will introduce electrical characterizations of Ge nanowire back-gate FETs fabricated using the Ge nanowire heterostructures. Specifically, the effect of $\mathrm{Al}_{2} \mathrm{O}_{3}$ capping layer on the device performance is studied in this section. Finally, we will discuss the possible research directions for future work on the Ge nanowire heterostructures, especially for promising applications in spintronics and further study on the growth dynamics.

\section{Experimental Results}

The growth of Ge nanowires can be accomplished by a variety of techniques. In this study, two popular methods were employed to synthesize single-crystalline Ge nanowire with $\langle 111\rangle$ growth direction. One is the supercritical fluidliquid-solid (SFLS) approach, in which Ge nanowires were produced in highly pressurized supercritical fluids enriched with organogermane precursors and metal nanocrystals as catalyst $[22,23]$. The typical diameter of as-synthesized Ge nanowires is around $40-50 \mathrm{~nm}$ and the length could be more than $10 \mu \mathrm{m}$. The other approach is the vapor-liquid-solid (VLS) method, in which metal (such as Au) catalyzed Ge nanowires were grown on $\mathrm{SiO}_{2} / \mathrm{Si}(100)$ substrates by means of chemical vapor deposition (CVD) using a gaseous $\mathrm{Ge}$ precursor $\mathrm{GeH}_{4}$ [24]. The VLS-grown Ge nanowires are typically $70-80 \mathrm{~nm}$ in diameter and have lengths over $10 \mu \mathrm{m}$. The reported carrier mobility of VLS-grown Ge nanowires is higher than SFLS-synthesized Ge nanowires [13, 14], while the latter method is claimed to provide a better control of the nanowire size and a higher product yield $[23,25]$. In both two methods, Ge nanowires are not doped on purpose during growth, but unintentional doping usually occurs [26, 27].

To form $\mathrm{Ni}_{x} \mathrm{Ge} / \mathrm{Ge}$ nanowire heterostructures, SFLSsynthesized Ge nanowires diluted in isopropyl alcohol (IPA) were dispersed onto a $\mathrm{SiO}_{2} / \mathrm{Si}$ substrate. The top thermal $\mathrm{SiO}_{2}$ was about $330 \mathrm{~nm}$ thick. The Si substrate was degenerately doped with a resistivity of $1-5 \times 10^{-3} \Omega-\mathrm{cm}$, which served as a back gate for further device characterization. Ebeam lithography (EBL) was used to define Ni contacts to Ge nanowires. Before e-beam evaporation of about $120 \mathrm{~nm}$ thick Ni (with the purity of $99.995 \%$ and in vacuum at a pressure lower than $10^{-6}$ Torr), the sample was dipped into diluted hydrofluoric acid (HF) for $15 \mathrm{~s}$ to completely remove native oxide in the contact region. A field-emission scanning electron microscopy (JEOL JSM-6700 FESEM) was used to examine the sample morphology before and after the annealing process. Figures 1(a) and 1(b) show the device schematics before and after the thermal diffusion of $\mathrm{Ni}$ into the Ge nanowire. Figure 1(c) shows the SEM image of the as-fabricated Ge nanowire device showing a uniform contrast. Then the sample was annealed with rapid thermal annealing (RTA) in the ambient of $\mathrm{N}_{2}$ to allow $\mathrm{Ni}$ thermal intrusion into $\mathrm{Ge}$ nanowire and subsequently form $\mathrm{Ni}_{x} \mathrm{Ge} / \mathrm{Ge}$ heterostructures along the nanowire. In the previous study on the interfacial reactions of $\mathrm{Ni}$ thin film on $\mathrm{Ge}(111)$ substrate, the germanide phase formation sequence was found to be $\mathrm{Ni}_{2} \mathrm{Ge}$ and $\mathrm{NiGe}$ at increasing temperatures in the range of $160^{\circ} \mathrm{C}$ to $600^{\circ} \mathrm{C}$ [28]. Various annealing temperatures ranging from $400^{\circ} \mathrm{C}$ to $700^{\circ} \mathrm{C}$ were used in this study to optimize the formation of nanowire heterostructures. It is found out that $\mathrm{Ge}$ nanowires were easily broken at a high annealing temperature $\left(>550^{\circ} \mathrm{C}\right)$ due to the significant reduction of the melting point for $\mathrm{Ge}$ nanowires compared with that of bulk Ge [29]. When the temperature decreased to $400^{\circ} \mathrm{C}-500^{\circ} \mathrm{C}$, clear diffusion of $\mathrm{Ni}$ into the Ge nanowire was also observed and the formed germanide was identified to be $\mathrm{Ni}_{2} \mathrm{Ge}$ (refer to the TEM analysis later). Figure 1(d) shows the SEM image of the Ge nanowire device upon RTA at $500^{\circ} \mathrm{C}$ for $60 \mathrm{~s}$, in which clear contrast was observed between the Ge nanowire and the formed nickel germanide nanowire due to the conductivity difference. The remained Ge region was easily controlled down to $650 \mathrm{~nm}$, and it can be further reduced to sub-100 nm $[11,16]$. Similar contrast was also observed after RTA at $400^{\circ} \mathrm{C}$ for $40 \mathrm{~s}$, as shown in Figure 1(e).

In order to identify the phase of the formed germanide and the epitaxial relationship of germanide-germanium interface, in situ TEM was used to study the formation process and reaction kinetics. To prepare the TEM sample, the single-crystalline Ge nanowires were dispersed on the TEM grid with a square opening of a $\mathrm{Si}_{3} \mathrm{~N}_{4}$ thin film. The lowstress $\mathrm{Si}_{3} \mathrm{~N}_{4}$ film was deposited by low-pressure chemical vapor deposition (LPCVD). The $\mathrm{Si}_{3} \mathrm{~N}_{4}$ film was about $50 \mathrm{~nm}$ thick, which provided a reliable mechanical support for Ge nanowire devices during the fabrication process and at the same time to assure it is transparent to the electron 
TABLE 1: Summary of Si and Ge nanowire heterostructures formed by solid-state reactions between a semiconductor nanowire and metal contacts.

\begin{tabular}{|c|c|c|c|}
\hline Material system & Annealing condition $\left({ }^{\circ} \mathrm{C}\right)$ & Formed silicide/germanide & Metal diffusion source \\
\hline $\mathrm{Ni}-\mathrm{Si}[6]$ & 550 & $\mathrm{NiSi}$ & Ni contact pad \\
\hline Ni-Si [7] & 470 & $\mathrm{NiSi}_{x}$ (not identified) & Ni contact pad \\
\hline Ni-Si [8] & $500-700$ & $\mathrm{NiSi}$ & Ni nanowire \\
\hline \multirow[b]{2}{*}{ Co-Si [9] } & 700 & $\mathrm{CoSi}$ & Co nanodots \\
\hline & 800 & $\mathrm{Co}_{2} \mathrm{Si}$ & Co nanodots \\
\hline Pt-Si [10] & 520 & PtSi & Pt contact pad \\
\hline Mn-Si [11] & 650 & $\mathrm{MnSi}$ & Mn contact pad \\
\hline Ni-Ge [13] & $400-500$ & $\mathrm{Ni}_{2} \mathrm{Ge}$ & Ni contact pad \\
\hline Ni-Ge [14] & 450 (capped with $\mathrm{Al}_{2} \mathrm{O}_{3}$ ) & $\mathrm{Ni}_{2} \mathrm{Ge} / \mathrm{NiGe}$ & Ni contact pad \\
\hline Ni-Ge [15] & $300-450$ & $\mathrm{Ni}_{2} \mathrm{Ge}$ & Ni contact pad \\
\hline $\mathrm{Cu}-\mathrm{Ge}[16-18]$ & 310 & $\mathrm{Cu}_{3} \mathrm{Ge}$ & $\mathrm{Cu}$ contact pad \\
\hline
\end{tabular}

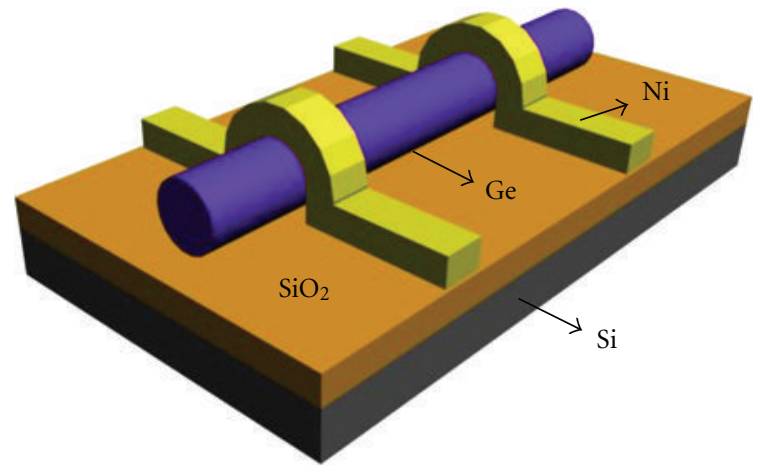

(a)

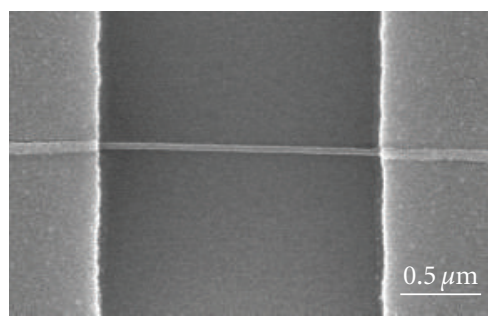

(c)

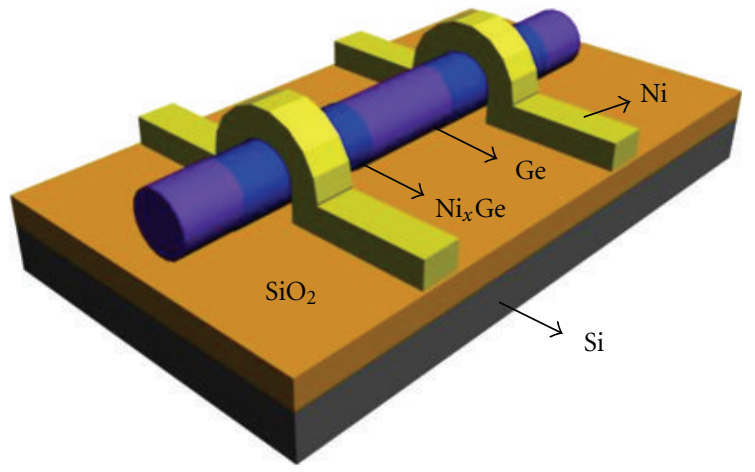

(b)

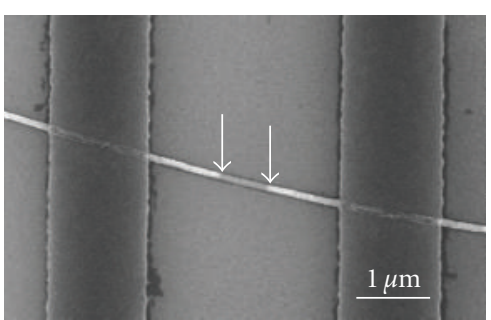

(d)

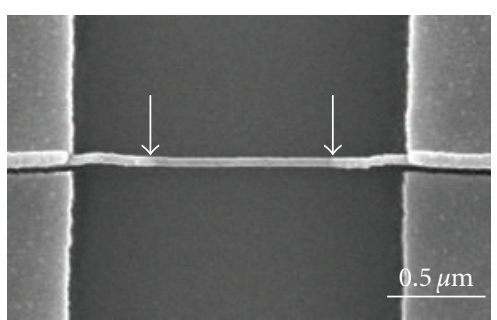

(e)

Figure 1: Formation of $\mathrm{Ni}_{2} \mathrm{Ge} / \mathrm{Ge} / \mathrm{Ni}_{2} \mathrm{Ge}$ heterostructures. Schematic illustration showing (a) before and (b) after the diffusion process of Ni into the Ge nanowire forming a $\mathrm{Ni}_{2} \mathrm{Ge} / \mathrm{Ge} / \mathrm{Ni}_{2} \mathrm{Ge}$ heterostructure. (c) SEM image of the Ge nanowire device with EBL defined Ni electrodes. (d) SEM image of the $\mathrm{Ni}_{2} \mathrm{Ge} / \mathrm{Ge} / \mathrm{Ni}_{2} \mathrm{Ge}$ heterostructure after RTA at $500^{\circ} \mathrm{C}$ for $60 \mathrm{~s}$ in which the length of the Ge region was easily controlled to submicron range. The arrows indicate the growth tips of the $\mathrm{Ni}_{2} \mathrm{Ge}$ nanowire. (e) SEM image of the $\mathrm{Ni}_{2} \mathrm{Ge}_{\mathrm{Ge}} / \mathrm{Ni}{ }_{2} \mathrm{Ge}$ heterostructure after $\mathrm{RTA}$ at $400^{\circ} \mathrm{C}$ for $40 \mathrm{~s}$. The arrows indicate the growth tips of the $\mathrm{Ni}_{2} \mathrm{Ge}$ nanowire. Reproduced from [13].

beam without interference with images of the nanowires. EBL-defined $\mathrm{Ni}$ pads were employed as the $\mathrm{Ni}$ diffusion source. A JEOL-2010 TEM (operated at $200 \mathrm{KV}$ with a pointto-point resolution of $0.25 \mathrm{~nm}$ ) attached with an energy dispersive spectrometer (EDS) was used to investigate the microstructures and to determine the compositions of the samples. To in situ observe the reactions of the Ni electrodes with Ge nanowires, the samples were heated inside TEM with a heating holder (Gatan 652 double tilt heating holder connected with a power supply to heat up the samples to the desired temperature) under a RTA mode with a pressure below $10^{-6}$ Torr. Figures $2(\mathrm{a})-2(\mathrm{c})$ show high-resolution TEM (HRTEM) images of the formed $\mathrm{Ni}_{x} \mathrm{Ge} / \mathrm{Ge}$ interface upon $500^{\circ} \mathrm{C}$ annealing. According to the lattice-resolved HRTEM analysis, the formed germanide was identified to be single-crystalline $\mathrm{Ni}_{2} \mathrm{Ge}$ with an orthorhombic lattice structure and lattice constants $a=0.511 \mathrm{~nm}, b=0.383 \mathrm{~nm}$, and $c=0.726 \mathrm{~nm}$ (space group 62). It was observed that a large lattice mismatch of $56.3 \%$ at the $\mathrm{Ni}_{2} \mathrm{Ge} / \mathrm{Ge}$ epitaxial interface could result in the segregation of nanoparticles (see Figure 4). In Figure 2(b), a clean and sharp interface between $\mathrm{Ni}_{2} \mathrm{Ge} / \mathrm{Ge}$ was observed with an approximately $1 \mathrm{~nm} \mathrm{GeO}_{x}$ 


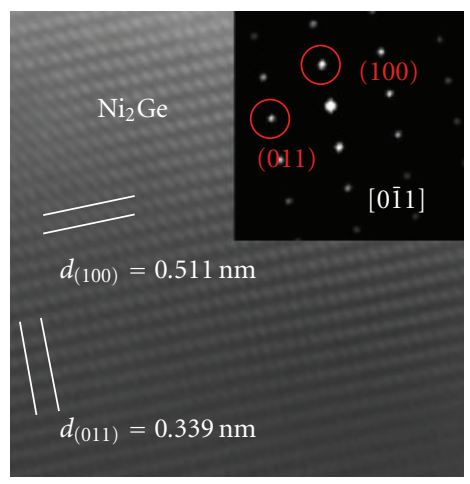

(a)

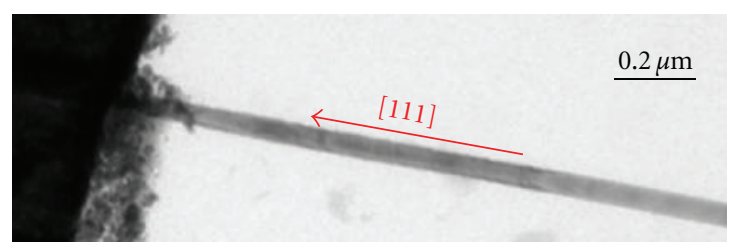

(d)

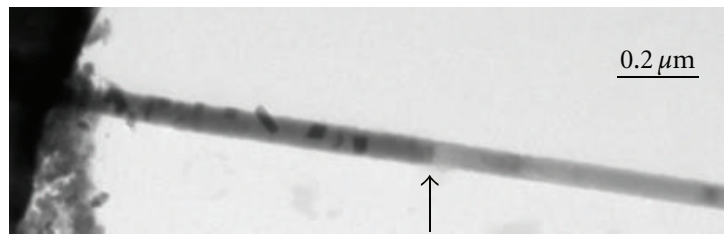

(e)

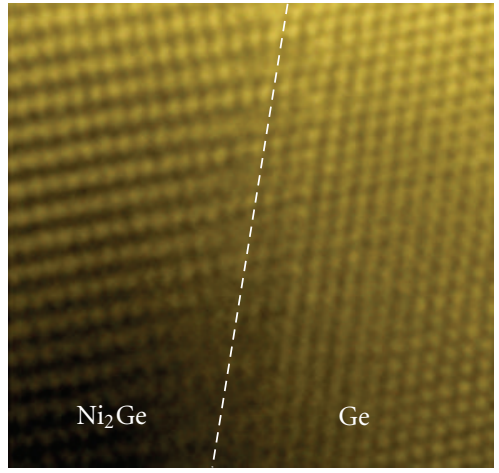

(b)

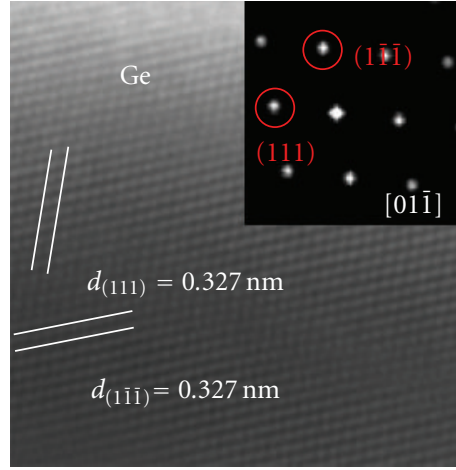

(c)

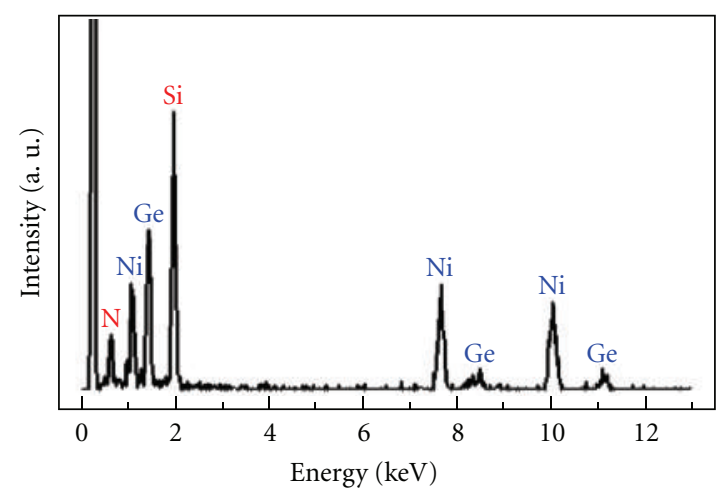

(f)

FIGURE 2: Epitaxial relationship at the $\mathrm{Ni}_{2} \mathrm{Ge} / \mathrm{Ge}$ interface. (a) Lattice-resolved TEM image of the formed $\mathrm{Ni}_{2} \mathrm{Ge}$ nanowire. The inset shows the FFT pattern, confirming that the formed germanide phase is $\mathrm{Ni}_{2} \mathrm{Ge}$. (b) TEM image of $\mathrm{Ni}_{2} \mathrm{Ge} / \mathrm{Ge}$ heterostructure showing an atomically sharp interface. (c) Lattice-resolved TEM image of the unreacted Ge nanowire. The inset shows the FFT pattern. (d) Low magnification TEM image of the as-fabricated device with the Ni pad and the Ge nanowire. (e) Low magnification TEM image after annealing at $500^{\circ} \mathrm{C}$. The arrow indicates the interface of the $\mathrm{Ni}_{2} \mathrm{Ge} / \mathrm{Ge}$ nanowire. (f) EDS of $\mathrm{Ni}_{2} \mathrm{Ge}$, showing a relative $2: 1$ concentration ratio of Ni and $\mathrm{Ge}$ atoms. Reproduced from [13].

shell surrounding both the $\mathrm{Ge}$ and $\mathrm{Ni}_{2} \mathrm{Ge}$ regions. The insets in Figures 2(a) and 2(c) illustrate the fast Fourier transform (FFT) patterns of $\mathrm{Ni}_{2} \mathrm{Ge}$ and Ge HRTEM images, respectively. The crystallographic epitaxial relationships between Ge and $\mathrm{Ni}_{2} \mathrm{Ge}$ are shown to be $\mathrm{Ge}[01 \overline{1}] / / \mathrm{Ni}_{2} \mathrm{Ge}[0 \overline{1} 1]$ and $\mathrm{Ge}(1 \overline{1} \overline{1}) / / \mathrm{Ni}_{2} \mathrm{Ge}(100)$, as we discussed. Figures $2(\mathrm{~d})$ and $2(\mathrm{e})$ show the low-magnification TEM images of Ge NWs before and after annealing at $500^{\circ} \mathrm{C}$, respectively. Figure 2 (f) shows the EDS of the formed germanide nanowire region, showing that the ratio of $\mathrm{Ni}$ to Ge concentration is about $2: 1$, which further support the fact that the formed germanide phase is $\mathrm{Ni}_{2} \mathrm{Ge}$. The signals of $\mathrm{Si}$ and $\mathrm{N}$ peaks are contributed from the $\mathrm{Si}_{3} \mathrm{~N}_{4}$ window.

Real-time observation on the $\mathrm{Ni}_{2} \mathrm{Ge}$ growth in a $\mathrm{Ge}$ nanowire was performed using in situ TEM video, which allows us to obtain lattice-resolved TEM images of the epitaxial interface in progression and thus to estimate the growth velocity. Figure 3 (a) shows the relation of $\mathrm{Ni}_{2} \mathrm{Ge}$ nanowire length versus the reaction time at 400 and $500^{\circ} \mathrm{C}$, illustrating a potentially linear growth behavior of $\mathrm{Ni}_{2} \mathrm{Ge}$ in the Ge nanowires, while the detailed growth mechanism requires further study. Figures 3(b), 3(c), 3(d), and 3(e) show the in situ TEM images of the $\mathrm{Ni}_{2} \mathrm{Ge}$ nanowire growth at 400 and $500^{\circ} \mathrm{C}$, respectively. The growth length of the $\mathrm{Ni}_{2} \mathrm{Ge}$ nanowire is $138.9 \mathrm{~nm}$ for $455 \mathrm{~s}$ at $400^{\circ} \mathrm{C}$ and $357.5 \mathrm{~nm}$ for $340 \mathrm{~s}$ at $500^{\circ} \mathrm{C}$, respectively. Based on the data collected on more than three nanowires, the extracted growth velocities are about $0.31 \mathrm{~nm} / \mathrm{s}$ at $400^{\circ} \mathrm{C}$ and $1.05 \mathrm{~nm} / \mathrm{s}$ and $500^{\circ} \mathrm{C}$, respectively. Using the Arrhenius plot [8], the activation energy of the $\mathrm{Ni}_{2} \mathrm{Ge}$ growth in the Ge nanowire is estimated to be $0.55 \pm 0.05 \mathrm{eV} /$ atom.

As mentioned above, due to a large lattice mismatch on the $\mathrm{Ni}_{2} \mathrm{Ge} / \mathrm{Ge}$ epitaxial interface, the resulting huge strain in the $\mathrm{Ni}_{2} \mathrm{Ge} / \mathrm{Ge} / \mathrm{Ni}_{2} \mathrm{Ge}$ nanowire heterostructure could lead to the segregation of $\mathrm{Ni}_{2} \mathrm{Ge}$ nanoparticles on the $\mathrm{Ni}_{2} \mathrm{Ge}$ nanowire after a long-time annealing. Figure 4(a) shows the TEM image of an as-fabricated Ge nanowire device with EBL-defined $\mathrm{Ni}$ pads at room temperature. Figures 4(b)4(d) are a series of in situ TEM images of the Ge nanowire device upon $400^{\circ} \mathrm{C}, 450^{\circ} \mathrm{C}$ and $500^{\circ} \mathrm{C}$ sequential annealing, respectively. The time clocks shown at the lower-right corner in each TEM image were captured in the form of hour: minute:second. Volume expansion and segregation to form nanoparticles were clearly observed. Figure 4(e) shows a 


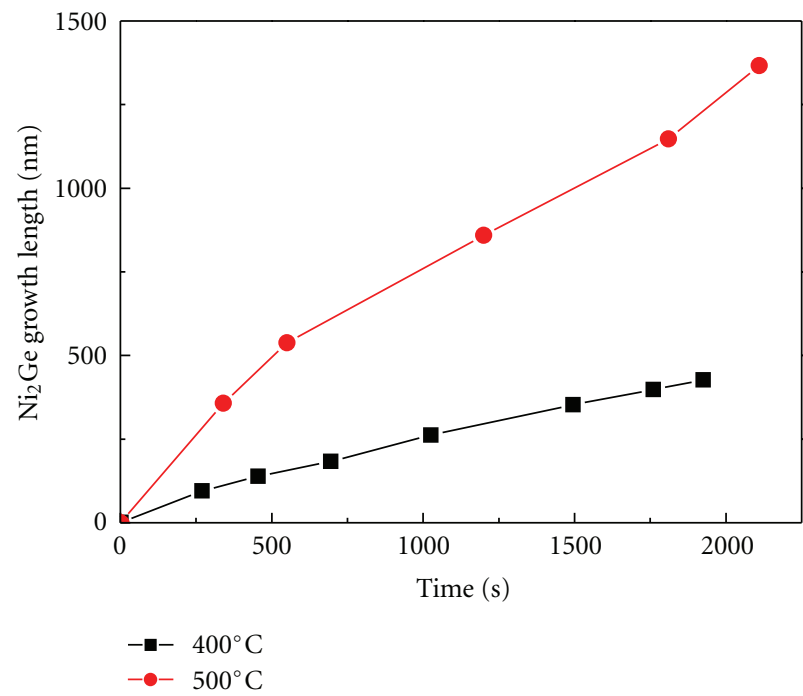

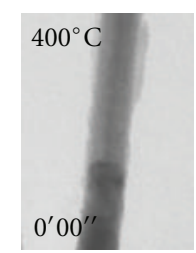

(b)

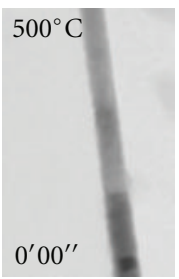

(d)

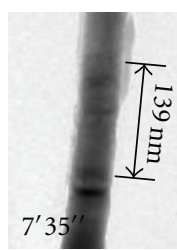

(c)

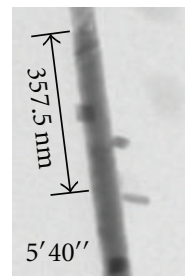

(e)

(a)

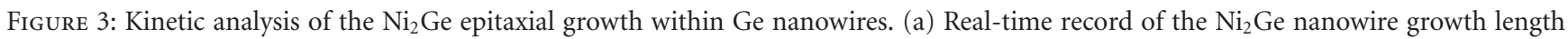

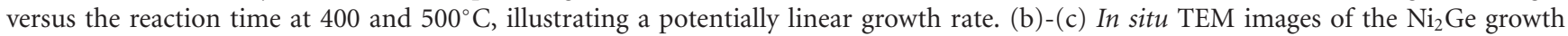
within a Ge nanowire at $400^{\circ} \mathrm{C}$ annealing. The arrow indicates a corresponding length of $138.9 \mathrm{~nm}$ growth in $7 \mathrm{~min} 35 \mathrm{sec}$. (d)-(e) In situ TEM images of the $\mathrm{Ni}_{2} \mathrm{Ge}$ growth within a Ge nanowire at $500^{\circ} \mathrm{C}$ annealing. The arrow indicates a corresponding length of $357.5 \mathrm{~nm}$ growth in $5 \mathrm{~min} 40 \mathrm{sec}$. Reproduced from [13].

TEM image of another Ge nanowire device annealed at $400^{\circ} \mathrm{C}$ for $30 \mathrm{~min}$. The results in Figures $4(\mathrm{c})-4(\mathrm{e})$ clearly demonstrate that as a result of strain release, $\mathrm{Ni}_{2} \mathrm{Ge}$ nanoparticles were formed and segregated on the $\mathrm{Ni}_{2} \mathrm{Ge}$ nanowire as $\mathrm{Ni}$ diffused along the formed $\mathrm{Ni}_{2} \mathrm{Ge}$ nanowire.

Similarly, the segregation of nanoparticles during annealing was also observed in the Ni-Si nanowire system as reported by Weber et al. [7]. For Si, a thin layer of high-quality native oxide is usually formed on the Si nanowire surface, while Ge does not have a stable native oxide. It is observed that the $\mathrm{SiO}_{2}$ shell has a substantial confinement effect on the nickel silicide growth along with phase transformation in a Si nanowire [30]. We studied the effect of oxide confinement on the germanide growth in a Ge nanowire; an oxide layer, such as $\mathrm{Al}_{2} \mathrm{O}_{3}$, was deposited to cap the Ge nanowire device before the annealing process, as shown in the schematics of Figure 5(a). Figure 5(b) shows the SEM image of the asfabricated $\mathrm{Ge}$ nanowire device showing uniform contrast. Prior to RTA, $20 \mathrm{~nm}$ thick $\mathrm{Al}_{2} \mathrm{O}_{3}$ was deposited on top by atomic layer deposition (ALD) at $250^{\circ} \mathrm{C}$ (Figure $5(\mathrm{c})$ ). It was noticed that the diameter of the Ge nanowire was increased after the $\mathrm{Al}_{2} \mathrm{O}_{3}$ deposition since ALD provided a conformal coverage. After that the sample was then annealed with RTA in $\mathrm{N}_{2}$ ambient to allow for the thermal intrusion of $\mathrm{Ni}$ into the Ge nanowire and subsequently form the $\mathrm{Ni}_{x} \mathrm{Ge} / \mathrm{Ge}$ heterostructures along the nanowire. Clear diffusion of $\mathrm{Ni}$ into the Ge nanowire was observed in both SEM and TEM, and the formed germanide was analyzed in HRTEM, as to be explained further later. Figure $5(\mathrm{~d})$ shows the SEM image of the $\mathrm{Ni}_{x} \mathrm{Ge} / \mathrm{Ge} / \mathrm{Ni}_{x} \mathrm{Ge}$ heterostructures after RTA at $450^{\circ} \mathrm{C}$ for $20 \mathrm{~s}$. Clear contrast was observed between the Ge nanowire and the formed nickel germanide nanowire, which is again attributed to the conductivity difference of the two. Figure 5(e) schematically illustrates the formation of $\mathrm{Ni}_{x} \mathrm{Ge} / \mathrm{Ge} / \mathrm{Ni}_{x} \mathrm{Ge}$ nanowire heterostructure with the $\mathrm{Al}_{2} \mathrm{O}_{3}$ confinement. The red line indicates the position where the device was cut with focused ion beam (FIB) to study the cross-sectional structure, as to be explained in Figure 6.

Figure 6(a) shows the low-magnification cross-sectional TEM image of the $\mathrm{Ni}_{x} \mathrm{Ge} / \mathrm{Ge}$ nanowire heterostructure, which was cut with FIB from the Ge nanowire device fabricated on a $\mathrm{SiO}_{2} / \mathrm{Si}$ wafer, as shown in Figure 5(e). Before FIB cutting, a $200 \mathrm{~nm}$-thick Pt film was deposited on top to protect the $\mathrm{Ni}_{x} \mathrm{Ge} / \mathrm{Ge} / \mathrm{Ni}_{x} \mathrm{Ge}$ nanowire heterostructure from the ion beam bombardment. When preparing the crosssection of $\mathrm{Ni}_{x}$ Ge for TEM analysis using FIB, we chose the position as close as to the $\mathrm{Ni}_{x} \mathrm{Ge} / \mathrm{Ge}$ interface. It is noted that in the cross-sectional view, there were some nanoparticles segregated on the $\mathrm{SiO}_{2}$ surface from the bottom of the formed nickel germanide, the region that was not confined by the $\mathrm{Al}_{2} \mathrm{O}_{3}$ capping layer. This result also explains the fact that we did not observe nanoparticles on the $\mathrm{Al}_{2} \mathrm{O}_{3}$ capped surface from the SEM image shown in Figure 5(d). Figure 6(b) shows the lattice-resolved HRTEM image of the interface between the formed NiGe nanowire and the segregated NiGe nanoparticle, which were both identified to be NiGe from the FFT pattern shown in the inset of Figure $6(\mathrm{~b})$. NiGe has an orthorhombic lattice structure with lattice constants $a=0.538 \mathrm{~nm}, b=0.342 \mathrm{~nm}$, and $c=$ $0.581 \mathrm{~nm}$ (space group 62). In order to further confirm the germanide phase, an EDS line scan was performed through 


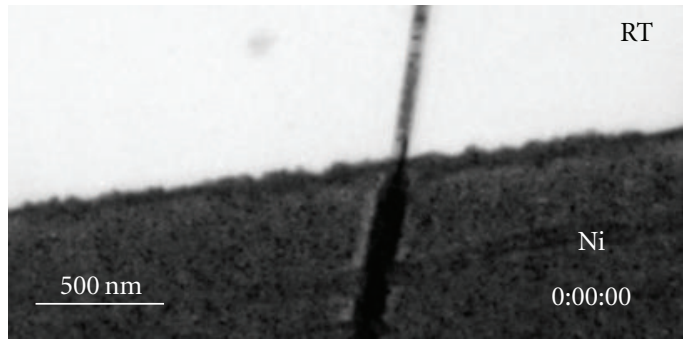

(a)

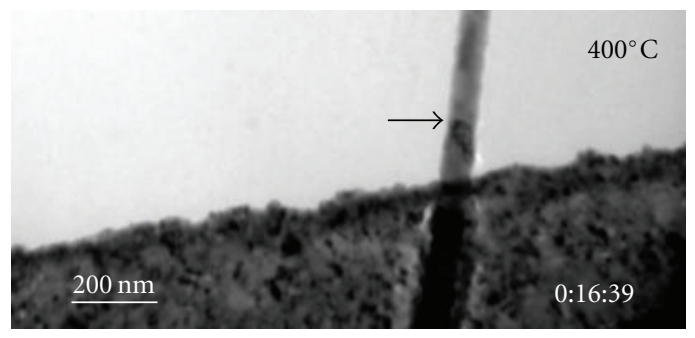

(b)

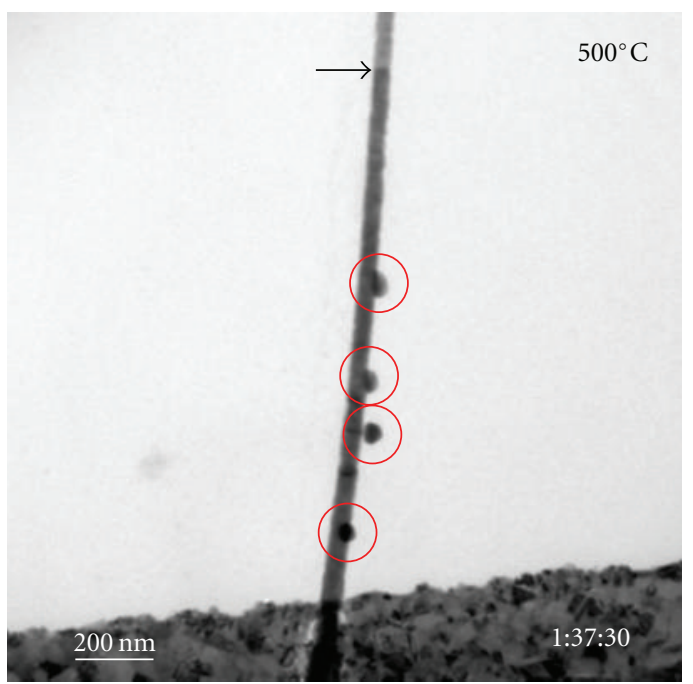

(d)

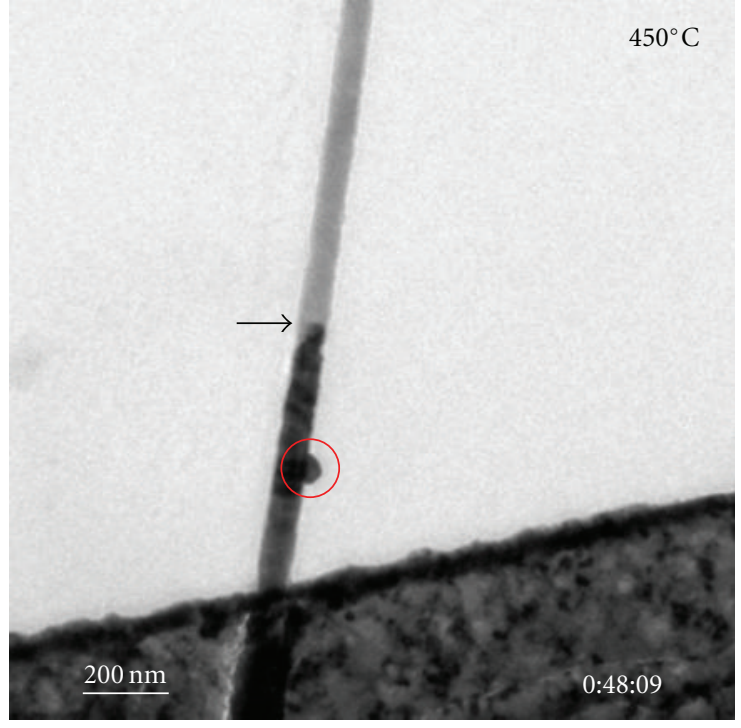

(c)

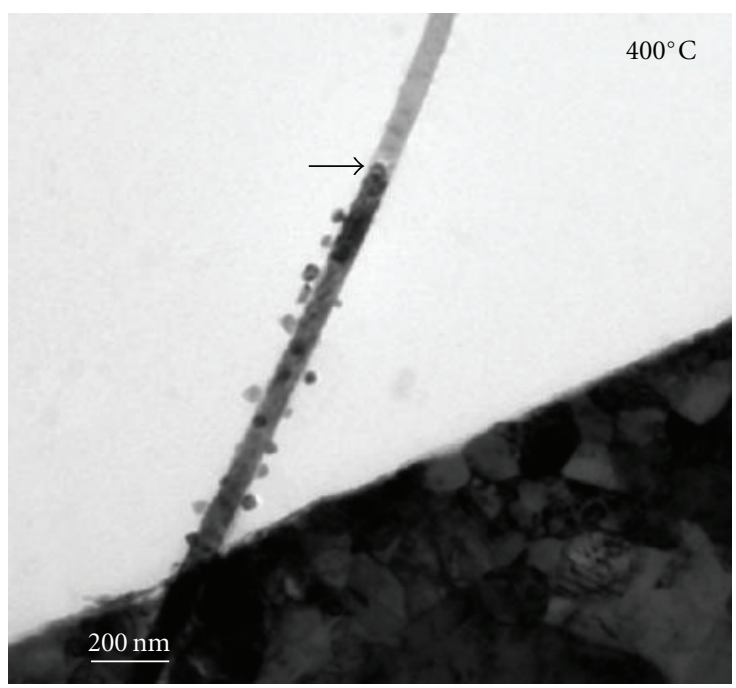

(e)

FIgURE 4: A series of in situ TEM images at various annealing temperatures: (a) room temperature; (b) $400^{\circ} \mathrm{C}$; (c) $450^{\circ} \mathrm{C}$; (d) $500^{\circ} \mathrm{C}$. The arrows indicate the interface between the formed $\mathrm{Ni}_{2} \mathrm{Ge}$ and the Ge nanowire. The red circles indicate $\mathrm{Ni}_{2} \mathrm{Ge}$ nanoparticles segregated from the $\mathrm{Ni}_{2} \mathrm{Ge}$ nanowire. (e) TEM image of the $\mathrm{Ni}$ electrode reacted with a Ge nanowire upon $400^{\circ} \mathrm{C}$ annealing for 30 min. Reproduced from [13].

the $\mathrm{Al}_{2} \mathrm{O}_{3}$-capped $\mathrm{Ni}_{x} \mathrm{Ge}$ nanowire to determine the profiles of $\mathrm{Ge}, \mathrm{Ni}, \mathrm{Al}$ and $\mathrm{O}$ atoms, as shown in the cross-sectional TEM image in Figure 6(c) as well as the individual line-scan profile in Figures 6(d) $-6(\mathrm{~g})$. From Figures $6(\mathrm{~d})$ and 6(e), the $\mathrm{Ni} / \mathrm{Ge}$ ratio was estimated to be about $1: 1$, which further proved the NiGe phase.

To study the epitaxial relationships between $\mathrm{Ni}_{x} \mathrm{Ge}$ and $\mathrm{Ge}$, the VLS-grown Ge nanowires were dispersed on the TEM grids with a square opening of a $\mathrm{Si}_{3} \mathrm{~N}_{4}$ thin film, as described above. The sample preparation was similar to the process as explained above for the $\mathrm{Ni}_{2} \mathrm{Ge} / \mathrm{Ge} / \mathrm{Ni}_{2} \mathrm{Ge}$ nanowire heterostructure. The only difference is that before the annealing process, an $\mathrm{Al}_{2} \mathrm{O}_{3}$ film was deposited by $\mathrm{ALD}$ at $250^{\circ} \mathrm{C}$ to cap the device and confine the solid state reaction of germanidation during annealing. The $\mathrm{Al}_{2} \mathrm{O}_{3}$ coated devices were then annealed both in situ (inside TEM) and ex situ (in RTA). Figure 7(a) shows the lowmagnification TEM image of the Ni-Ge nanowire device capped with $10 \mathrm{~nm} \mathrm{Al}_{2} \mathrm{O}_{3}$ after annealing at $450^{\circ} \mathrm{C}$ for $30 \mathrm{~s}$. The enlarged TEM image in Figure 7(b) shows that there are clearly two interfaces in the $\mathrm{Ni}_{x} \mathrm{Ge} / \mathrm{Ge}$ nanowire heterostructure. Figure $7(\mathrm{c})$ shows the EDS line-scan profile from the nanowire heterostructure. The line profile indicates two germanide phases in the formed $\mathrm{Ni}_{x} \mathrm{Ge}$ region, which corresponds to the two interfaces observed in the $\mathrm{Ni}_{x} \mathrm{Ge} / \mathrm{Ge}$ heterostructure. The Ni/Ge ratio is about $1: 1$ in the small 


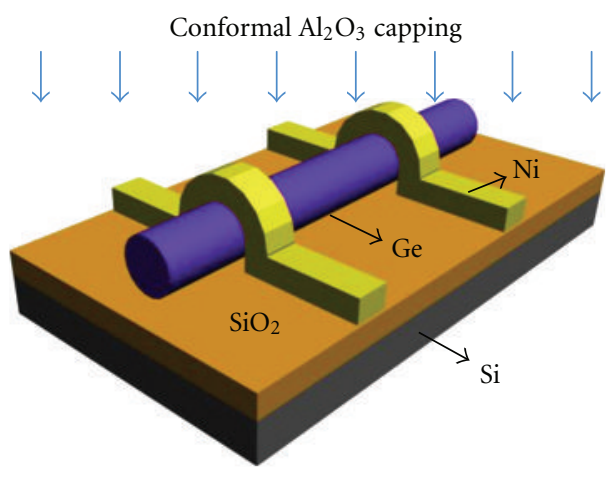

(a)

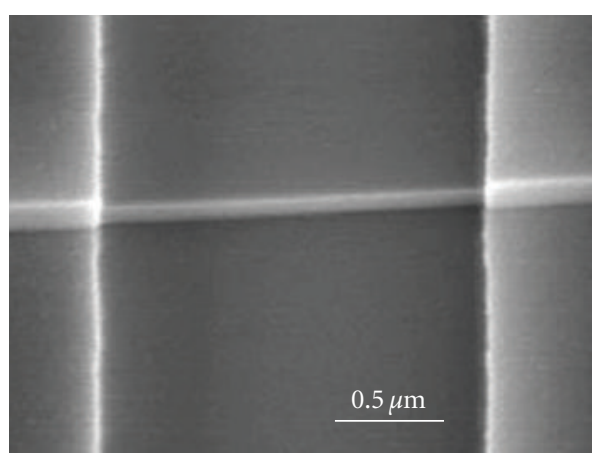

(b)

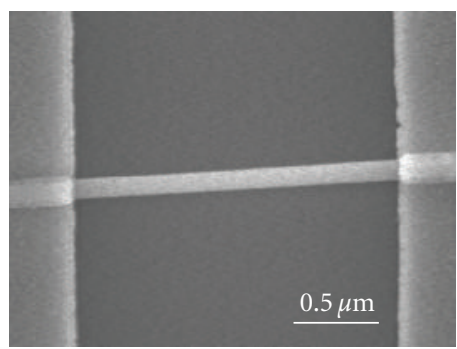

(c)

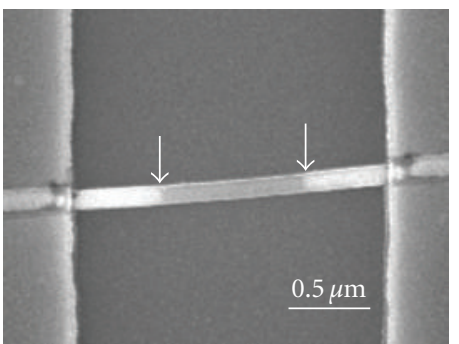

(d)

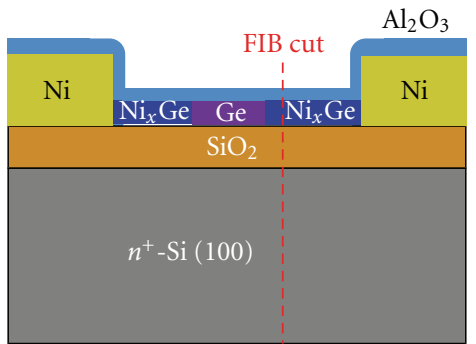

(e)

Figure 5: Formation of $\mathrm{Ni}_{x} \mathrm{Ge} / \mathrm{Ge} / \mathrm{Ni}_{x} \mathrm{Ge}$ heterostructure with the $\mathrm{Al}_{2} \mathrm{O}_{3}$ confinement. (a) Schematic illustration of an $\mathrm{Al}_{2} \mathrm{O}_{3}$ conformal capping on the Ge nanowire device by ALD. (b) SEM image of the as-fabricated Ge nanowire device with EBL-defined Ni electrodes. (c) SEM image of the Ge nanowire device after a conformal capping of $20 \mathrm{~nm}$ thick $\mathrm{Al}_{2} \mathrm{O}_{3}$. (d) SEM image of the $\mathrm{Ni}_{x} \mathrm{Ge}_{\mathrm{Ge}} / \mathrm{Ni}_{x} \mathrm{Ge}$ heterostructure after RTA at $450^{\circ} \mathrm{C}$ for $20 \mathrm{~s}$ in which the length of the Ge region was easily controlled to be several hundred nanometers. The arrows indicate the growth tip of the $\mathrm{Ni}_{x} \mathrm{Ge}$ nanowire. (e) Schematic illustration showing the formation of $\mathrm{Ni}_{x} \mathrm{Ge} / \mathrm{Ge} / \mathrm{Ni}_{x} \mathrm{Ge}$ nanowire heterostructure with the $\mathrm{Al}_{2} \mathrm{O}_{3}$ confinement. The red line indicates the position chosen for FIB to study the cross-sectional structure in Figure 6. Reproduced from [14].

germanide region close to the $\mathrm{Ni}_{x} \mathrm{Ge} / \mathrm{Ge}$ interface, suggesting the formation of NiGe. This result is consistent with the line-scan profile in Figures 6(d) and 6(e). The length of the $\mathrm{NiGe}$ region can range from tens of nanometers to hundreds of nanometers in our experiments. On the other hand, the $\mathrm{Ni} / \mathrm{Ge}$ ratio is about $2: 1$ in the other germanide region close to the $\mathrm{Ni}$ pad on the left, implying that the phase is $\mathrm{Ni}_{2} \mathrm{Ge}$. It is also worth noting that the almost constant concentration of $\mathrm{Ge}$ along the heterostructure suggests $\mathrm{Ni}$ is the dominant diffusion species in this system [28]. Figure $7(\mathrm{~d})$ shows the lattice-resolved HRTEM image of the $\mathrm{Ni}_{x} \mathrm{Ge} / \mathrm{Ge}$ heterostructure, clearly exhibiting two interfaces. The FFT patterns at the $\mathrm{Ni}_{2} \mathrm{Ge}, \mathrm{NiGe}$, and Ge regions are shown in Figures $7(\mathrm{e})-7(\mathrm{~g})$, which help further confirm the germanide phases. The crystallographic epitaxial relationships between the Ge/NiGe interface were determined to be $\mathrm{Ge}[01 \overline{1}] / / \mathrm{NiGe}[010]$ and $\mathrm{Ge}(1 \overline{1} \overline{1}) / / \mathrm{NiGe}(001)$, while those for the $\mathrm{Ni}_{2} \mathrm{Ge} / \mathrm{NiGe}$ interface were $\mathrm{Ni}_{2} \mathrm{Ge}[100] / / \mathrm{NiGe}[010]$ and $\mathrm{Ni}_{2} \mathrm{Ge}(011) / / \mathrm{NiGe}(001)$. It is worth noting that a large lattice mismatch of $77.7 \%$ observed at the NiGe/Ge epitaxial interface could result in the segregation of nanoparticles (see Figure 6). In contrast, the epitaxial relationships in the $\mathrm{Ni}_{2} \mathrm{Ge} / \mathrm{Ge} / \mathrm{Ni}_{2} \mathrm{Ge}$ nanowire heterostructure formed without oxide confinement during annealing were found to be $\mathrm{Ge}[01 \overline{1}] / / \mathrm{Ni}_{2} \mathrm{Ge}[0 \overline{1} 1]$ and $\mathrm{Ge}(1 \overline{1} \overline{1}) / / \mathrm{Ni}_{2} \mathrm{Ge}(100)$, as we discussed [13]. Therefore, the $\mathrm{Al}_{2} \mathrm{O}_{3}$ capping layer plays an important role in confining the growth of germanides and also promoting the formation of NiGe to maintain highquality epitaxial relationships between $\mathrm{Ni}_{2} \mathrm{Ge}$ and $\mathrm{Ge}$.

Figure 8 schematically illustrates the epitaxial relationships of the $\mathrm{Ni}_{2} \mathrm{Ge} / \mathrm{Ge}$ interface in the $\mathrm{Ni}_{2} \mathrm{Ge} / \mathrm{Ge} / \mathrm{Ni}_{2} \mathrm{Ge}$ nanowire heterostructure and the $\mathrm{NiGe} / \mathrm{Ge}$ interface in the $\mathrm{Ni}_{2} \mathrm{Ge} / \mathrm{NiGe} / \mathrm{Ge} / \mathrm{NiGe} / \mathrm{Ni}_{2} \mathrm{Ge}$ nanowire heterostructure. According to the epitaxial relationships in both cases, the nanowire growth direction (along the Ge [111] direction) is not perpendicular to the epitaxial planes (parallel to the Ge $(1 \overline{1} \overline{1})$ plane). This "twisted" growth mode of nanowires is substantially different from that in the typical epitaxial growth of thin films, in which the growth direction is usually perpendicular to the epitaxial planes [31]. The presence of the oxide capping may alter the energy of the growth and thus change the twisted angle. Furthermore, it suggests that the twisting in nanowires may be used to accommodate substantially large lattice mismatches. This unique growth mode may be attributed to the fact in minimizing the total system energy in the presence of a large lattice mismatch in the interface. Further microscopic studies in simulation and experiment are required to understand the growth kinetics for this unique growth mode in one-dimensional systems.

The formed atomically sharp interface in the $\mathrm{Ni}_{x} \mathrm{Ge} / \mathrm{Ge} / \mathrm{Ni}_{x} \mathrm{Ge}$ nanowire heterostructures (both with and without $\mathrm{Al}_{2} \mathrm{O}_{3}$ capping during annealing) can be used 


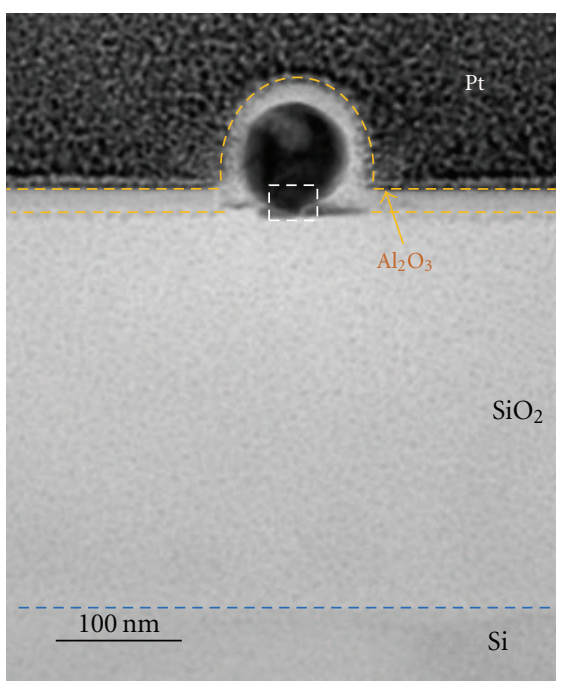

(a)

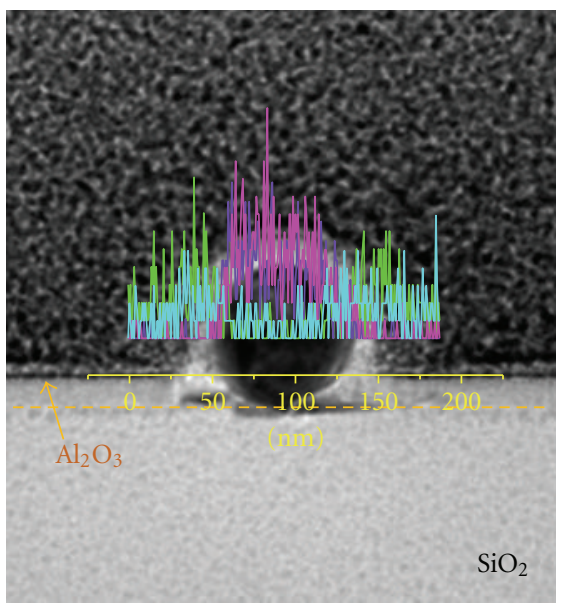

(c)

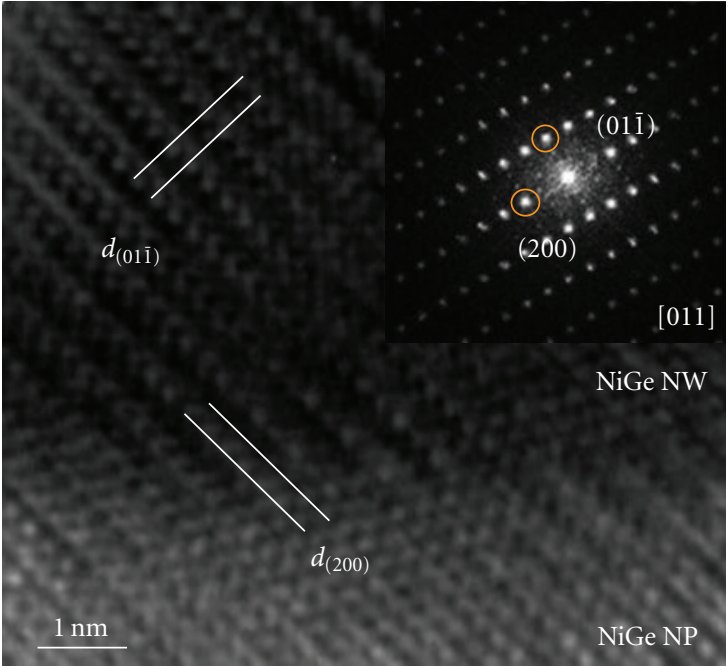

(b)

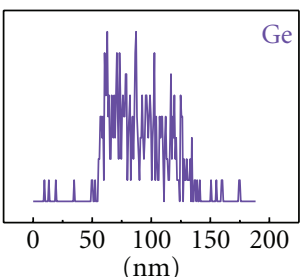

(d)

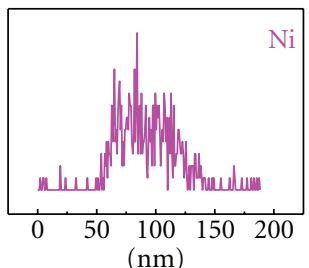

(e)

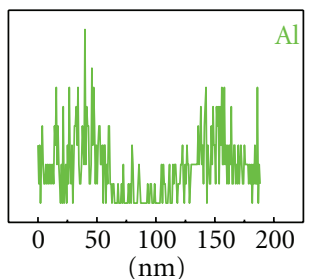

(f)

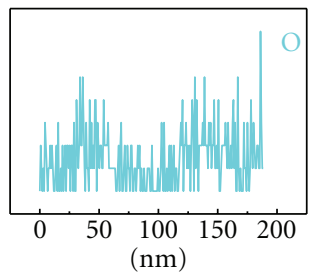

(g)

Figure 6: Cross-sectional TEM study of a Ni-Ge nanowire device on a $\mathrm{SiO}_{2} / \mathrm{Si}$ substrate cut with FIB. (a) Low-magnification cross-sectional TEM image of the NiGe region. The $20 \mathrm{~nm}$ thick $\mathrm{Al}_{2} \mathrm{O}_{3}$ film provides a conformal capping on the device surface and germanide nanoparticles are clearly observed as they segregated underneath the nanowire, the region that is not covered by $\mathrm{Al}_{2} \mathrm{O}_{3}$. (b) Lattice-resolved $\mathrm{HRTEM}$ image of the interface between the formed NiGe nanowire (NW) and the segregated NiGe nanoparticle (NP), as indicated by the white rectangle in Figure 5(a). The inset shows the corresponding FFT pattern. The labeled lattice spacings for NiGe are: $d_{(01-1)}=0.295 \mathrm{~nm}$ and $d_{(200)}=0.269 \mathrm{~nm}$. (c) Cross-sectional TEM image with the line-scan profiles of Ge, Ni, Al and O atoms. (d)-(g) The individual line-scan profile of $\mathrm{Ge}, \mathrm{Ni}, \mathrm{Al}$, and $\mathrm{O}$ atoms, respectively, The $\mathrm{Ni} / \mathrm{Ge}$ ratio is about $1: 1$. Reproduced from [14].

to explore promising applications in nanoscale devices $[6,7,10,16]$. As aforementioned, this $\mathrm{Ni}_{x} \mathrm{Ge} / \mathrm{Ge} / \mathrm{Ni}_{x} \mathrm{Ge}$ nanowire heterostructure can be easily used to fabricate Ge nanowire FETs, in which the germanide regions $\mathrm{Ni}_{x} \mathrm{Ge}$ can be used as source/drain contacts to the Ge nanowire channel. The channel length can be simply controlled by the annealing time and growth length of the germanide nanowire; therefore, it can be well controlled to sub-100 nm using a convenient RTA process. Clearly, this simple process has a great advantage over traditional complex and expensive photolithography technology in achieving short-channel transistors.
Back-gate FETs were fabricated on the $\mathrm{SiO}_{2} / \mathrm{Si}$ substrate to study the electrical transport property of the $\mathrm{Ni}_{2} \mathrm{Ge} / \mathrm{Ge} / \mathrm{Ni}_{2} \mathrm{Ge}$ nanowire heterostructure. The Si substrate is degenerately doped to serve as a back gate. The device schematic is shown in Figure 9(a), and electrical measurements were performed using a probe station with a Keithley 4200 semiconductor parameter analyzer. For comparison, Figure 9(b) shows the logarithm plot of typical $I_{\mathrm{ds}}-V_{\mathrm{gs}}$ curves for the Ge nanowire FET at various drain voltages before and after RTA. They both show a p-type transistor behavior, although we intended to grow undoped Ge nanowires. This is mainly due to the Fermi level pinning at the Ge nanowire 


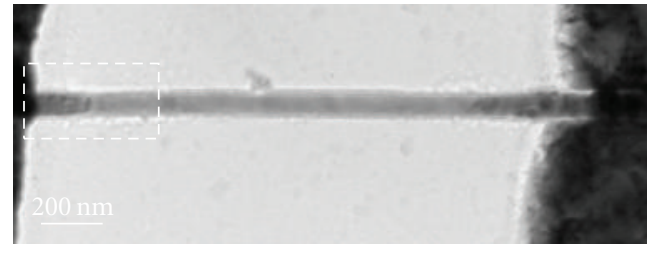

(a)

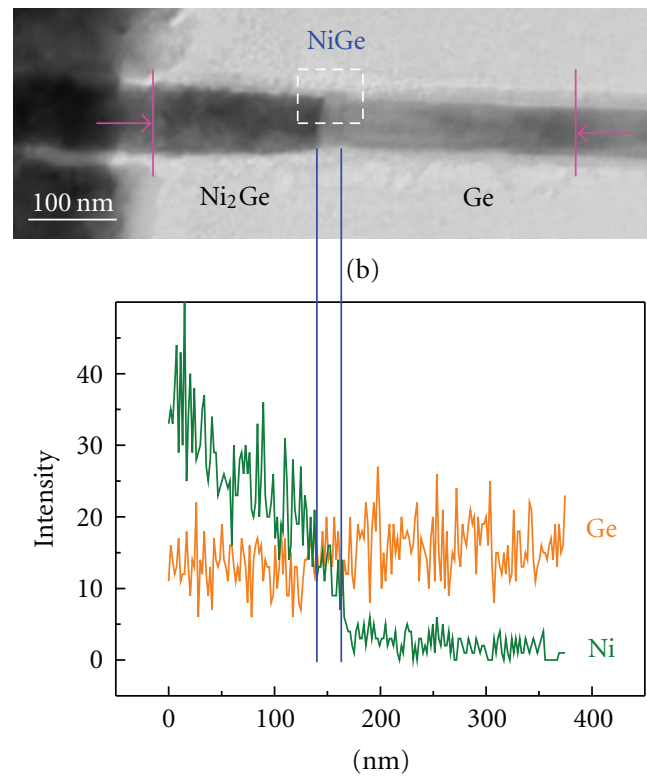

(c)

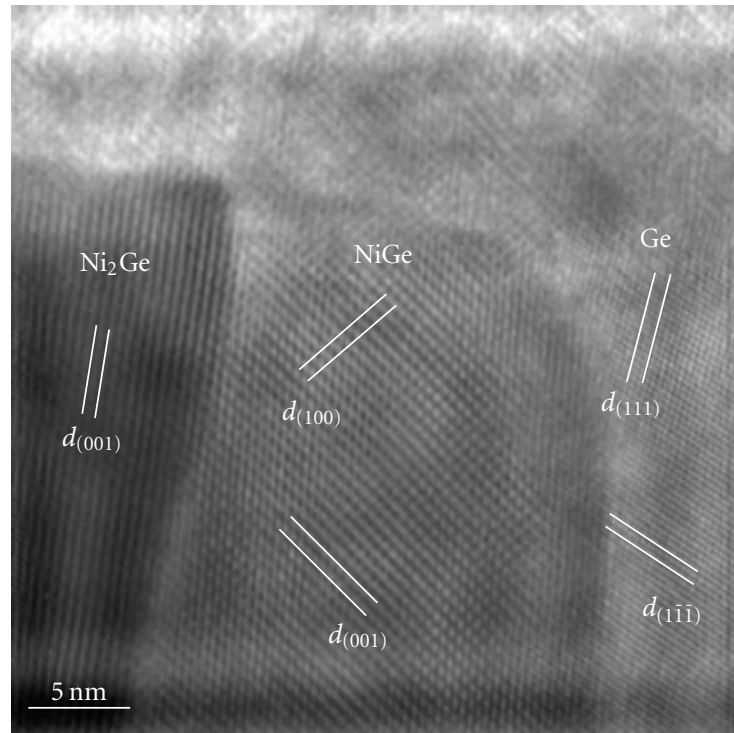

(d)

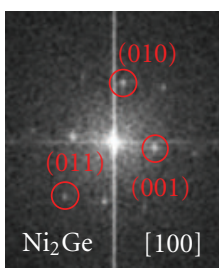

(e)

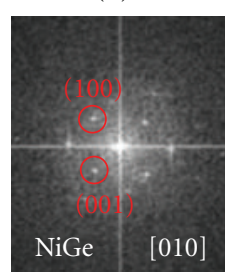

(f)

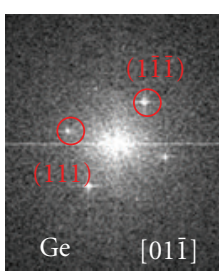

(g)

FIGURE 7: Plane-view TEM images of Ni-Ge nanowire devices on a TEM grid with a $50 \mathrm{~nm}$ thick $\mathrm{Si}_{3} \mathrm{~N}_{4}$ window. (a) Low-magnification TEM image of a Ge nanowire reacted with $120 \mathrm{~nm}$ thick Ni pads upon $450^{\circ} \mathrm{C}$ RTA for $30 \mathrm{~s}$. (b) Enlarged TEM image from the white rectangle in (a). These regions with different contrasts and compositions are labeled. (c) Corresponding EDS line-scan profiles of Ge and Ni across the region between two red lines in (b). (d) Lattice-resolved TEM image of the formed $\mathrm{Ni}_{x} \mathrm{Ge} / \mathrm{Ge}$ nanowire heterostructure from the white rectangle in (b). The labeled lattice spacings are: $d_{(001)}=0.5036 \mathrm{~nm}$ for $\mathrm{Ni}_{2} \mathrm{Ge} ; d_{(100)}=0.538 \mathrm{~nm}$ and $d_{(001)}=0.5811 \mathrm{~nm}$ for NiGe; $d_{(111)}=0.3265 \mathrm{~nm}$ and $d_{(1-1-1)}=0.3265 \mathrm{~nm}$ for Ge. (e)-(g) are the FFT patterns taken from the $\mathrm{Ni}_{2} \mathrm{Ge}, \mathrm{NiGe}$, and Ge regions in (d), respectively. Reproduced from $[14]$.

surface induced by Ge surface states, which tends to result in hole accumulation $[26,27]$. The maximum current measured before RTA at $V_{\mathrm{ds}}=0.5 \mathrm{~V}$ is about $30 \mathrm{nA}$, corresponding to a current density of $2.4 \times 10^{3} \mathrm{~A} / \mathrm{cm}^{2}$. The current density is relatively small due to a large Schottky barrier at the source/drain contacts before annealing. To extract the mobility, we first used the cylinder-on-plate model to estimate the gate capacitance coupling between the Ge nanowire and the back-gate oxide as

$$
C_{\mathrm{ox}}=\frac{2 \pi \varepsilon_{\mathrm{ox}} \varepsilon_{0} L}{\cosh ^{-1}\left(\left(r+t_{\mathrm{ox}}\right) / r\right)},
$$

(see [32]) where $\varepsilon_{0}=8.85 \times 10^{-14} \mathrm{~F} / \mathrm{cm}$ is the vacuum dielectric constant, $\varepsilon_{\mathrm{ox}}=3.9$ is the relative dielectric constant for $\mathrm{SiO}_{2}$, and $r=20 \mathrm{~nm}$ is the radius of the Ge nanowire. The Ge nanowire channel bis $L=3 \mu \mathrm{m}$, and the thickness of the back-gate dielectric is $t_{\mathrm{ox}}=330 \mathrm{~nm}$. Given the above parameters, the estimated gate capacitance is $C_{\mathrm{OX}}=1.83 \times$ $10^{-16} \mathrm{~F}$. The field effect hole mobility can be extracted from the $I_{\mathrm{ds}}-V_{\mathrm{gs}}$ curves using the transconductance $\left(g_{m}\right)$ at a fixed drain bias $V_{\mathrm{ds}}$

$$
\mu=\frac{g_{m} L^{2}}{V_{\mathrm{ds}} C_{\mathrm{ox}}} .
$$

Using the maximum transconductance extracted from the $I_{\mathrm{ds}}-V_{\mathrm{gs}}$ curves, the hole mobility obtained falls in the range of $3-8 \mathrm{~cm}^{2} / \mathrm{Vs}$. This is consistent with previous reported values (less than $10 \mathrm{~cm}^{2} / \mathrm{Vs}$ ) for SFLS-synthesized Ge nanowires [25].

After RTA at $400^{\circ} \mathrm{C}$ for $15 \mathrm{~s}$, however, electrical transport measurements on the Ge nanowire device show much improved transistor characteristics, as shown in Figure 9(b). The gate bias was scanned from $0 \mathrm{~V}$ to $-40 \mathrm{~V}$, the latter of which corresponds to a maximum vertical gate electrical field of $1.21 \times 10^{6} \mathrm{~V} / \mathrm{cm}$. The $I_{\mathrm{ds}}-V_{\mathrm{gs}}$ curves show a ptype behavior with an on/off ratio larger than $10^{3}$. The maximum current measured at $V_{\mathrm{ds}}=0.5 \mathrm{~V}$ is about $0.7 \mu \mathrm{A}$ corresponding to a current density of $5.6 \times 10^{4} \mathrm{~A} / \mathrm{cm}^{2}$, which was more than 20 times larger after annealing, in 


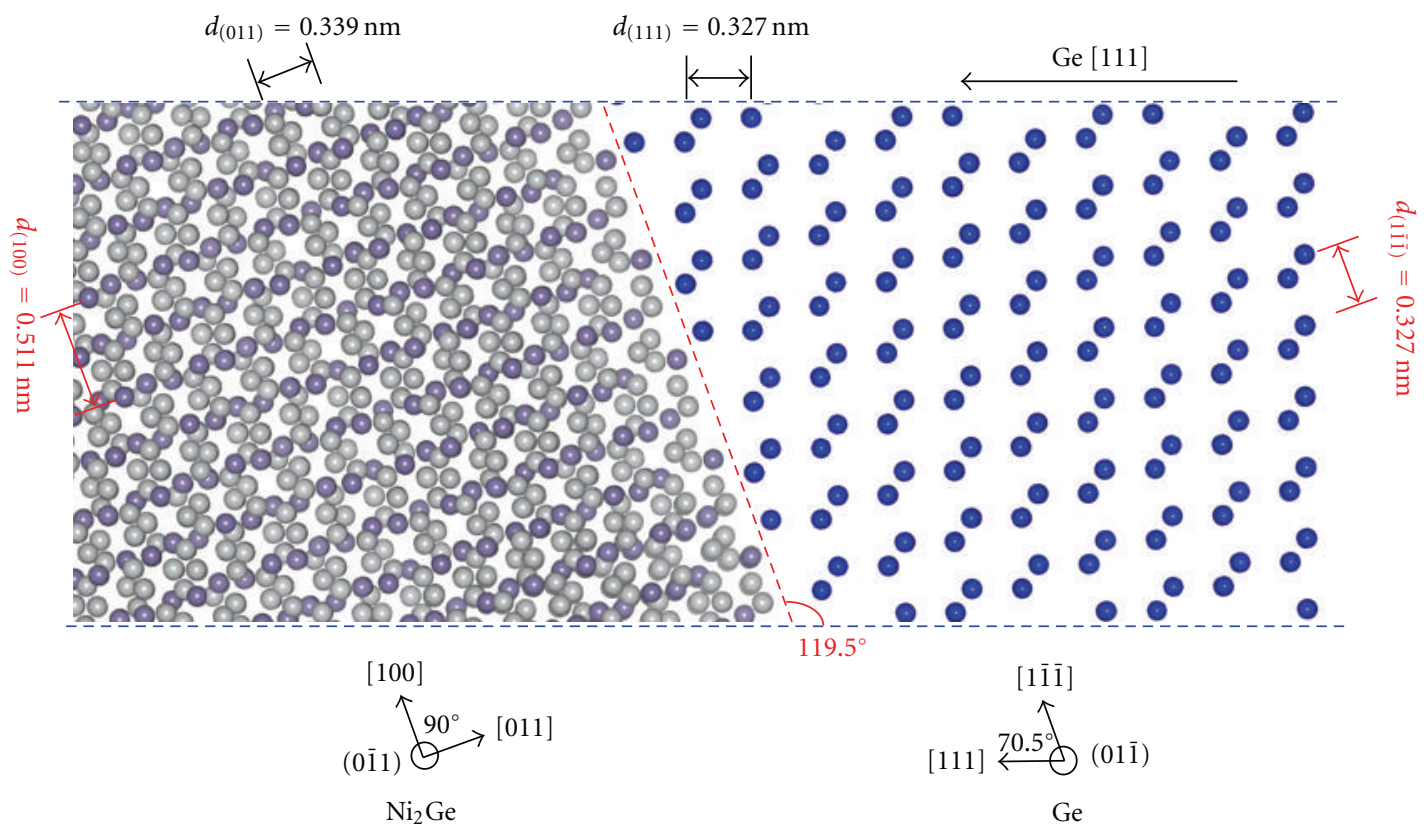

(a)

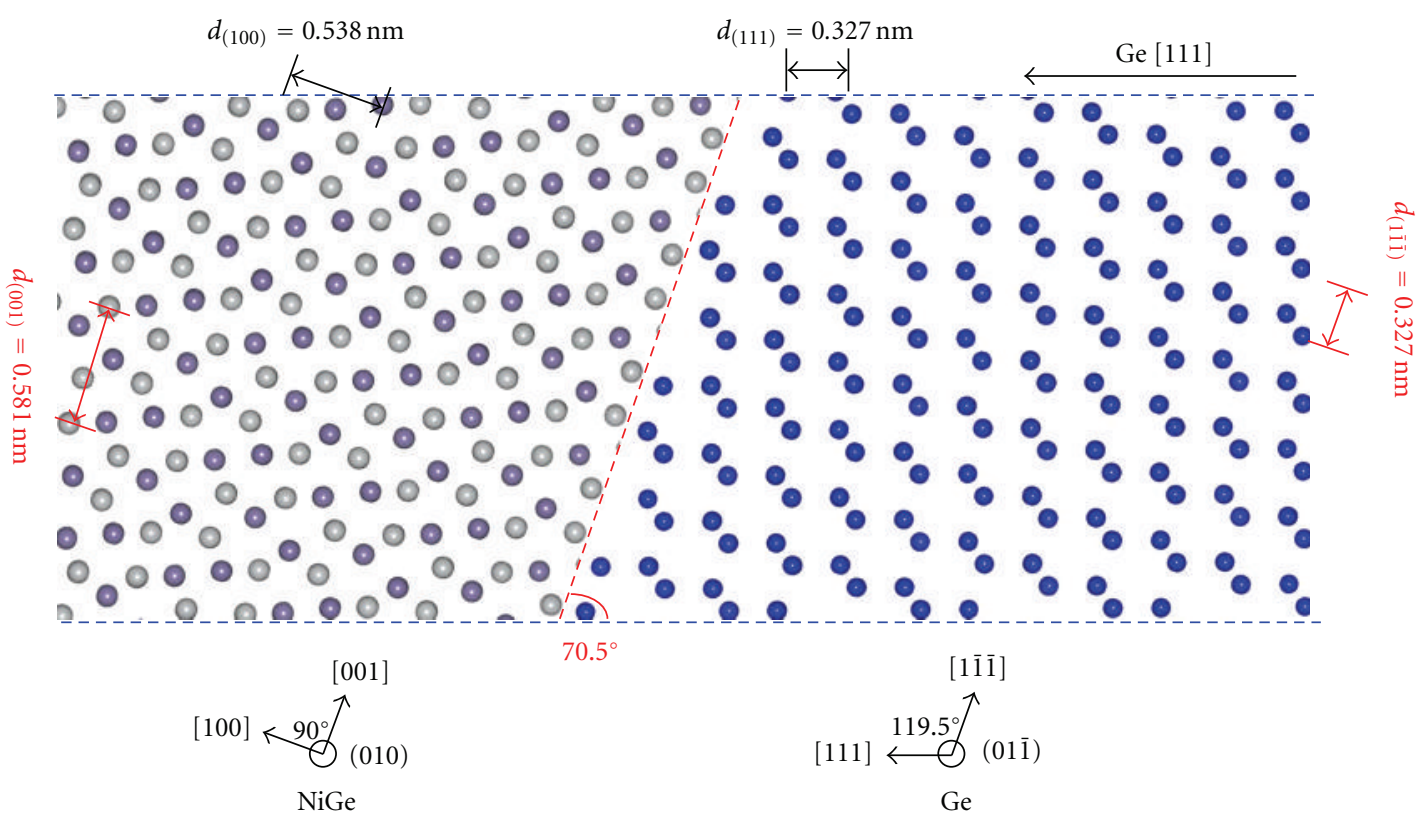

(b)

FIGURE 8: Schematic illustration of the epitaxial relationships of (a) the $\mathrm{Ni}_{2} \mathrm{Ge} / \mathrm{Ge}$ interface in the $\mathrm{Ni}_{2} \mathrm{Ge} / \mathrm{Ge} / \mathrm{Ni}_{2} \mathrm{Ge}$ nanowire heterostructure and (b) the $\mathrm{NiGe} / \mathrm{Ge}$ interface in the $\mathrm{Ni}_{2} \mathrm{Ge} / \mathrm{NiGe} / \mathrm{Ge} / \mathrm{NiGe} / \mathrm{Ni}_{2} \mathrm{Ge}$ nanowire heterostructure, respectively. Both of them show "twisted" but different growth modes. The grey and purple balls represent the $\mathrm{Ni}$ and $\mathrm{Ge}$ atoms in the $\mathrm{Ni}_{x} \mathrm{Ge}$ lattice, respectively, while the blue one represents the Ge atom in the Ge lattice. Reproduced from [14].

which the $\mathrm{Ni}_{2} \mathrm{Ge}$ contact to the Ge nanowire channel was developed. The maximum transconductance extracted from $I_{\mathrm{ds}}-V_{\mathrm{gs}}$ curves at drain bias $V_{\mathrm{ds}}=0.1 \mathrm{~V}$ is $13.3 \mathrm{nS}$, giving rise to a field-effect hole mobility of $65.2 \mathrm{~cm}^{2} / \mathrm{Vs}$. Although this mobility is still lower than the reported value from VLS-grown Ge nanowires $[14,16]$, it still shows about one order of magnitude improvement among SFLS-synthesized
Ge nanowires [25], and this increase may be attributed to the atomically sharp contact of $\mathrm{Ni}_{2} \mathrm{Ge}$ to the $\mathrm{Ge}$ nanowire.

Similarly, the $\mathrm{Ni}_{2} \mathrm{Ge} / \mathrm{NiGe} / \mathrm{Ge} / \mathrm{NiGe} / \mathrm{Ni}_{2} \mathrm{Ge}$ nanowire heterostructures formed with $\mathrm{Al}_{2} \mathrm{O}_{3}$ capping during annealing can also be used to fabricate Ge nanowire FETs. To further improve the transistor performance, VLS-grown nanowires were used in this study because of their higher 


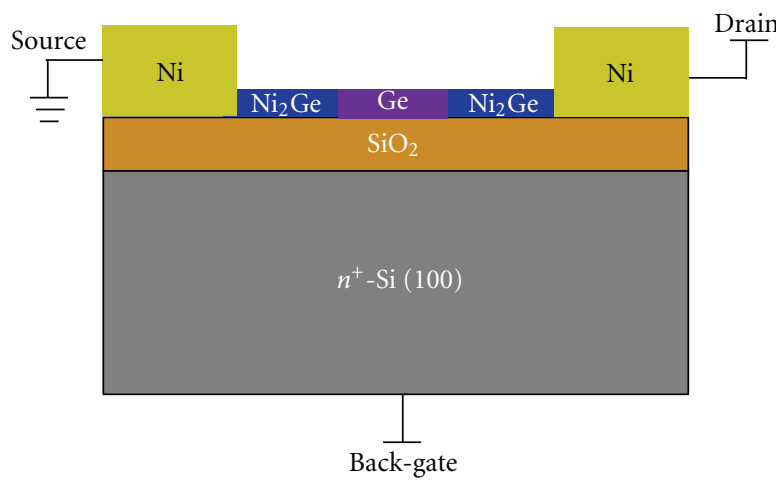

(a)

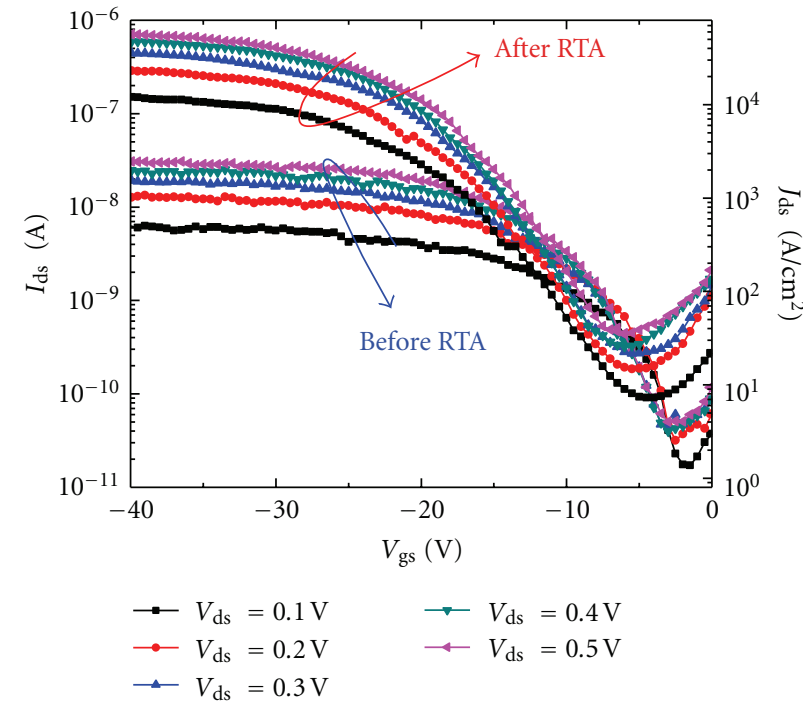

(b)

Figure 9: Electrical characterization of Ge nanowire back-gate FETs (without $\mathrm{Al}_{2} \mathrm{O}_{3}$ capping during annealing) at $300 \mathrm{~K}$. (a) Schematic illustration of a Ge nanowire back-gate FET. (b) $I_{\mathrm{ds}}-V_{\mathrm{gs}}$ curves of the back-gate Ge nanowire transistor before and after RTA, both showing a p-type MOSFET behavior. The transistor performance was significantly improved after RTA, in which the $\mathrm{Ni}_{2} \mathrm{Ge}$ source/drain contacts were formed. Reproduced from [13].

carrier mobility. Back-gate nanowire FETs were fabricated on the $\mathrm{SiO}_{2} / \mathrm{Si}$ substrate similarly as shown in Figure 10(a). Figure 10(b) shows the typical $I_{\mathrm{ds}}-V_{\mathrm{gs}}$ curves of a backgate $\mathrm{Ge}$ nanowire FET after RTA at $450^{\circ} \mathrm{C}$ for $20 \mathrm{~s}$, in which the on/off ratio is as high as $10^{5}$. The maximum transconductance is obtained to be about $0.168 \mu \mathrm{S}$ at $V_{\mathrm{ds}}=$ $0.1 \mathrm{~V}$, which gives rise to a normalized transconductance of $2.4 \mu \mathrm{S} / \mu \mathrm{m}$, assuming the effective channel length is equal to the nanowire diameter $(70 \mathrm{~nm})$ [10]. The extracted hole mobility in our experiments is typically in the range of $150-210 \mathrm{~cm}^{2} /$ Vs. Compared with SFLS-synthesized Ge nanowires, the significant improvement in the transistor performance here could be attributed to a better crystalline quality of VLS-grown Ge nanowires. Figure 10(c) shows the typical $I_{\mathrm{ds}}-V_{\mathrm{ds}}$ curves of a back-gate Ge nanowire FET at various gate voltages.

As explained above, the $\mathrm{Al}_{2} \mathrm{O}_{3}$ capping layer helps confine the growth of germanide in a $\mathrm{Ge}$ nanowire during thermal annealing. More importantly, it is of interest to study the effect of the $\mathrm{Al}_{2} \mathrm{O}_{3}$ capping layer on the device performance. In the previous study on the metal contacts to Ge substrate through a thin layer of $\mathrm{Al}_{2} \mathrm{O}_{3}$ tunneling oxide by $\mathrm{Zhou}$ et al., it is found that $\mathrm{Al}_{2} \mathrm{O}_{3}$ helps terminate the dangling bonds and passivate the Ge surface, therefore, alleviate Fermi level pinning effect [12]. In this study, dual sweepings of gate bias in the $I_{\mathrm{ds}}-V_{\mathrm{gs}}$ curves were performed to investigate the charge trapping due to the $\mathrm{Al}_{2} \mathrm{O}_{3}$ capping layer on passivating the Ge nanowire surface. Figure 10(d) shows the $I_{\mathrm{ds}}-V_{\mathrm{gs}}$ curves under various conditions: before $\mathrm{Al}_{2} \mathrm{O}_{3}$ deposition (both in air and in vacuum) and after $\mathrm{Al}_{2} \mathrm{O}_{3}$ deposition at $250^{\circ} \mathrm{C}$. The gate bias was swept from $+40 \mathrm{~V}$ to $-40 \mathrm{~V}$ then back to $+40 \mathrm{~V}$ in steps of $0.5 \mathrm{~V}$ at a fixed drain bias of $V_{\mathrm{ds}}=$
$20 \mathrm{mV}$. The $I_{\mathrm{ds}}-V_{\mathrm{gs}}$ curve measured in air before annealing shows the biggest hysteresis, which is mainly due to the absorption of molecules from the ambient and the charge trapping on the Ge surface $[26,33]$. The measured reduced hysteresis in a vacuum (less than $10^{-5}$ Torr), however, rules out the contribution from the ambient. Also, measurements in the vacuum help reduce scatterings from the molecules absorbed on the Ge surface as carriers transport along the Ge nanowire channel, which will reduce the resistance of Ge nanowires. Furthermore, the hysteresis was significantly reduced after the $\mathrm{Al}_{2} \mathrm{O}_{3}$ deposition, which unambiguously demonstrates the passivation effect of the $\mathrm{Al}_{2} \mathrm{O}_{3}$ layer on the $\mathrm{Ge}$ nanowire surface [12]. Besides, the $\mathrm{Al}_{2} \mathrm{O}_{3}$ passivation could again reduce scatterings for carriers transport along the Ge nanowire channel and thus further reduce the resistance of Ge nanowires. The small hysteresis present after $\mathrm{Al}_{2} \mathrm{O}_{3}$ passivation, however, may arise from the charge trapping on the Ge surface between the Ge nanowire channel and the back-gate dielectric, the region that is not covered by the $\mathrm{Al}_{2} \mathrm{O}_{3}$ capping layer.

\section{Conclusion and Discussion for Future Study}

In summary, Ge nanowire heterostructures with atomically sharp interfaces have been demonstrated by the solidstate reaction between a single-crystalline Ge nanowire and $\mathrm{Ni}$ contact pads via a facile rapid thermal annealing process in a temperature range of $400-500^{\circ} \mathrm{C}$. The crystallographic epitaxial relationships in the formation of the $\mathrm{Ni}_{2} \mathrm{Ge} / \mathrm{Ge} / \mathrm{Ni}_{2} \mathrm{Ge}$ nanowire heterostructure were determined 


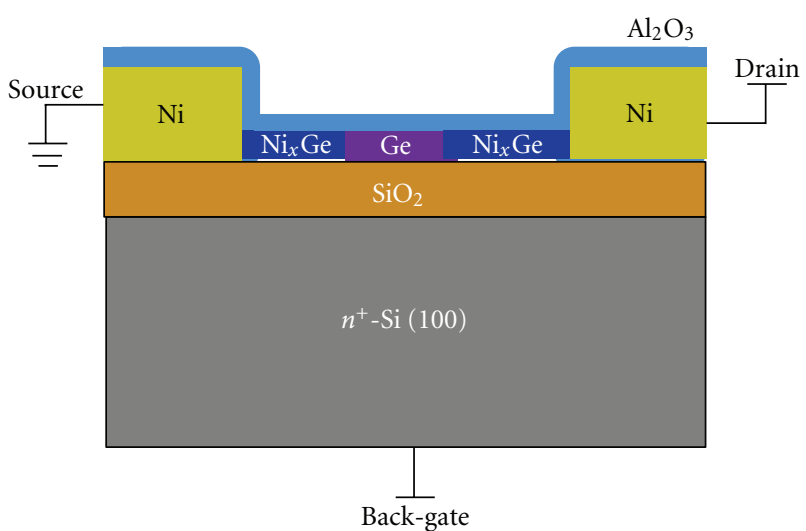

(a)

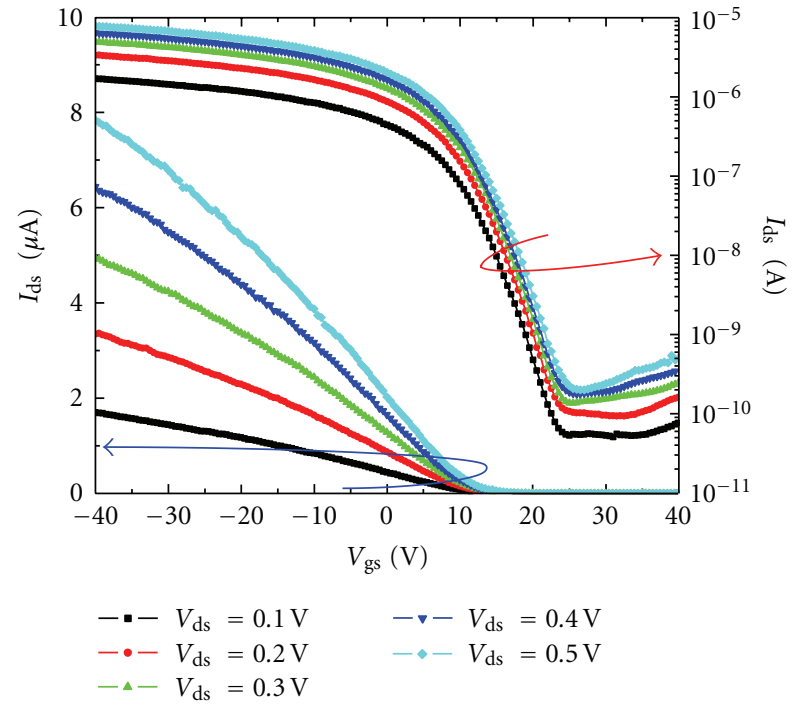

(b)

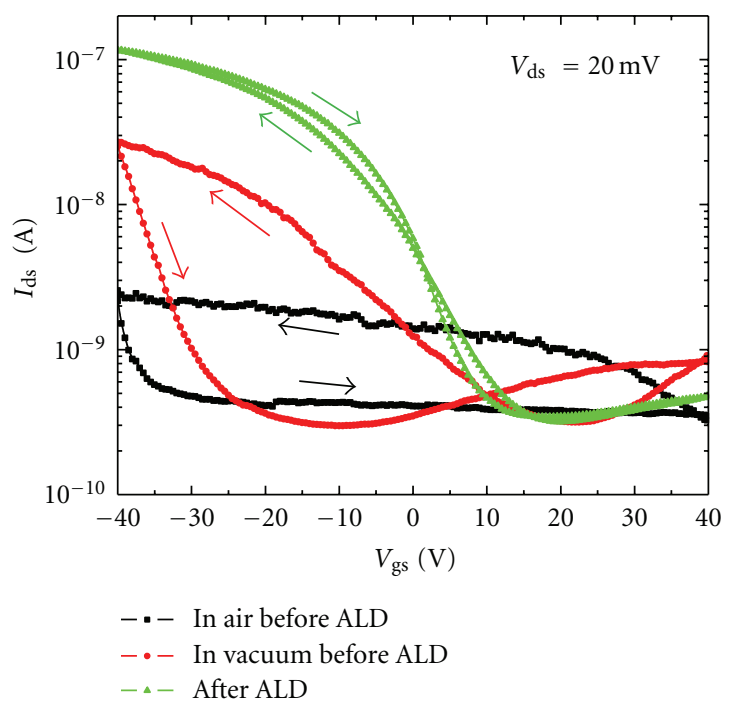

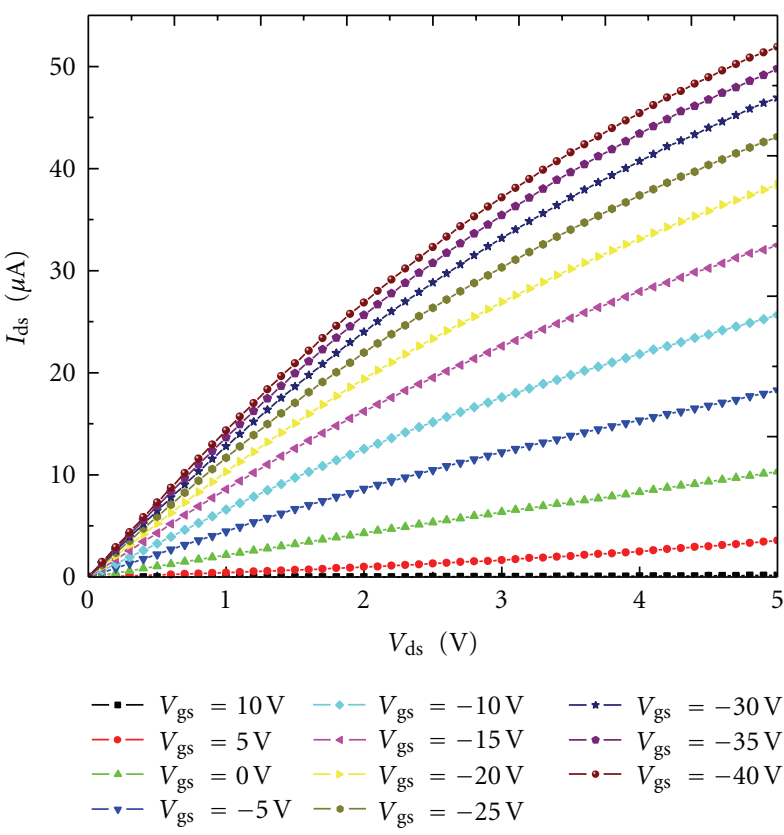

(c)

(d)

FIgURE 10: Electrical characteristics of Ge nanowire back-gate FETs (with $\mathrm{Al}_{2} \mathrm{O}_{3}$ capping during annealing) at $300 \mathrm{~K}$. (a) Schematic illustration of a Ge nanowire back-gate FET. (b) $I_{\mathrm{ds}}-V_{\mathrm{gs}}$ curves of the back-gate Ge nanowire transistor after RTA, showing a p-type MOSFET behavior. (c) $I_{\mathrm{ds}}-V_{\mathrm{ds}}$ curves of the back-gate Ge nanowire transistor after RTA. (d) Dual sweepings of the gate bias $V_{\mathrm{gs}}$ between $+40 \mathrm{~V}$ to $-40 \mathrm{~V}$ showing different sizes of hysteresis under various conditions. The arrows indicate the sweeping directions. The hysteresis was significantly reduced after $\mathrm{Al}_{2} \mathrm{O}_{3}$ passivation. A small hysteresis was still observed after ALD, which may be attributed to the charge trapping on the Ge surface between the Ge nanowire channel and the back-gate dielectric, the region that is not covered by the $\mathrm{Al}_{2} \mathrm{O}_{3}$ capping layer. $\mathrm{Reproduced}$ from [14].

to be $\mathrm{Ge}[01 \overline{1}] / / \mathrm{Ni}_{2} \mathrm{Ge}[0 \overline{1} 1]$ and $\mathrm{Ge}(1 \overline{1} \overline{1}) / / \mathrm{Ni}_{2} \mathrm{Ge}(100)$. Backgate FETs were fabricated using the formed $\mathrm{Ni}_{2} \mathrm{Ge}$ region as source/drain contacts to the Ge nanowire channel. The electrical measurement shows an on/off ratio over $10^{3}$ and a field-effect hole mobility of about $65.4 \mathrm{~cm}^{2} / \mathrm{Vs}$, which are superior to reported values for SFLS-synthesized Ge nanowires.
More importantly, the effect of oxide confinement on the formation of the Ge nanowire heterostructure was studied by capping the $\mathrm{Ge}$ nanowire device with a layer of $\mathrm{Al}_{2} \mathrm{O}_{3}$ before the annealing process. In contrast to the single germanide phase in the $\mathrm{Ni}_{2} \mathrm{Ge} / \mathrm{Ge} / \mathrm{Ni}_{2} \mathrm{Ge}$ nanowire heterostructure, a segment of high-quality epitaxial NiGe was then formed between $\mathrm{Ni}_{2} \mathrm{Ge}$ and Ge. The crystallographic epitaxial 


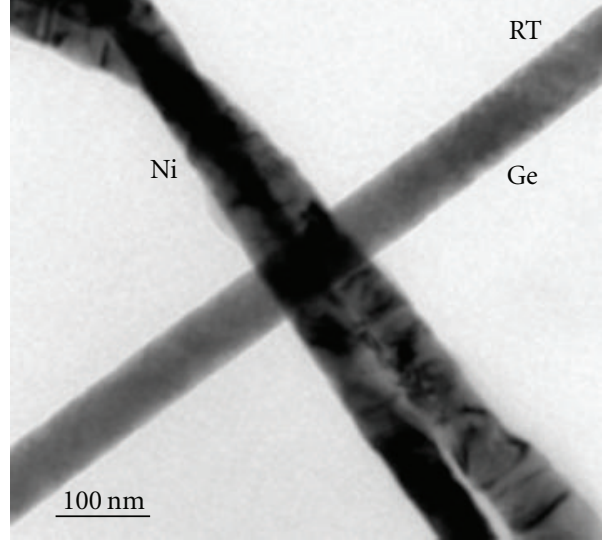

(a)

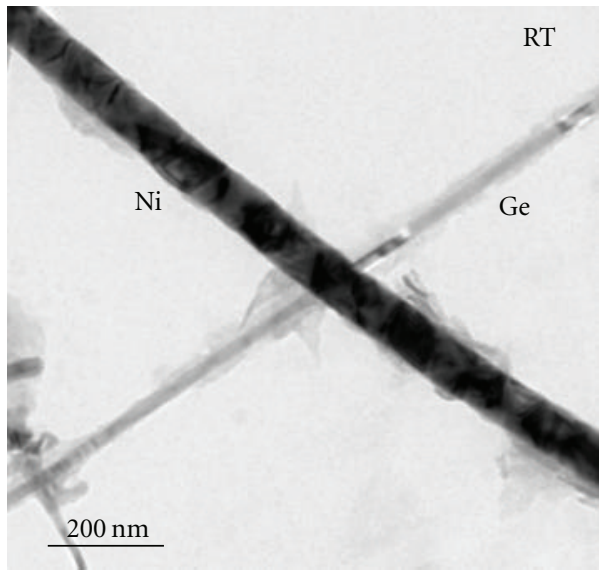

(c)

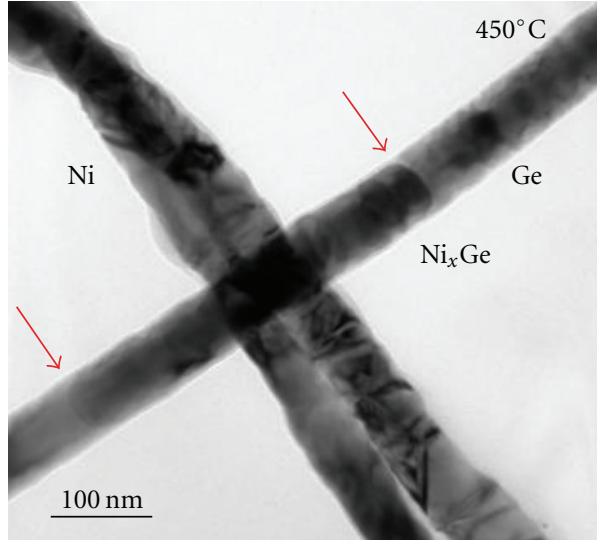

(b)

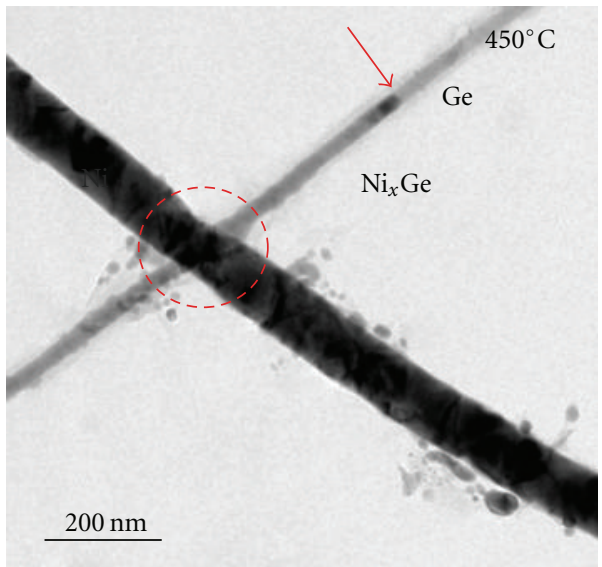

(d)

FIgure 11: (a) TEM image of a Ge nanowire in point-contact with two Ni nanowires on the TEM grid at room temperature. (b) TEM image showing the diffusion of $\mathrm{Ni}$ into the $\mathrm{Ge}$ nanowire upon $450^{\circ} \mathrm{C}$ annealing. The red arrows indicate the growth tip of the $\mathrm{Ni}_{x} \mathrm{Ge}$ nanowire. (c) TEM image of another Ge nanowire in point contact with a Ni nanowire on the TEM grid at room temperature. (d) TEM image showing the diffusion of $\mathrm{Ni}$ into the $\mathrm{Ge}$ nanowire upon $450^{\circ} \mathrm{C}$ annealing. The red circle highlights the consumption of $\mathrm{Ni}$ in the formation of the $\mathrm{Ni}_{x} \mathrm{Ge}$ nanowire upon annealing. Also, the segregation of $\mathrm{Ni}_{x} \mathrm{Ge}$ nanoparticles was not observed in the Ni-Ge nanowire point-contact system upon annealing.

relationships were determined to be $\mathrm{Ge}[01 \overline{1}] / / \mathrm{NiGe}[010]$ and $\mathrm{Ge}(1 \overline{1} \overline{1}) / / \mathrm{NiGe}(001)$ for the $\mathrm{Ge} / \mathrm{NiGe}$ interface and $\mathrm{Ni}_{2} \mathrm{Ge}[100] / / \mathrm{NiGe}[010]$ and $\mathrm{Ni}_{2} \mathrm{Ge}(011) / / \mathrm{NiGe}(001)$ for the $\mathrm{Ni}_{2} \mathrm{Ge} / \mathrm{NiGe}$ interface, respectively. Similarly, back-gate FETs were fabricated on the formed $\mathrm{Ni}_{2} \mathrm{Ge} / \mathrm{NiGe} / \mathrm{Ge} / \mathrm{NiGe} / \mathrm{Ni}_{2} \mathrm{Ge}$ nanowire heterostructure, and the electrical measurements reveal a high-performance p-type behavior, showing a high on/off ratio of $10^{5}$ and a field-effect hole mobility of about $210 \mathrm{~cm}^{2} /$ Vs. Moreover, the $\mathrm{Al}_{2} \mathrm{O}_{3}$ capping was found to passivate the Ge nanowire surface as well as to provide an appreciable confinement during the growth of germanide and changes its composition to maintain the high-quality epitaxial relationships.

For further understanding the growth kinetics of Ge nanowire heterostructures, a more detailed study is required $[8,9,34-36]$. For instance, the size of the metal diffusion (contact) source may affect the formation of Ge nanowire heterostructure, especially the segregation of nanoparticles.
In this paper, the metal source was defined with EBL and ebeam evaporation, in which the size of planar $\mathrm{Ni}$ contacts (typically in the $\mu \mathrm{m}$ range) is much larger than the diameter of $\mathrm{Ge}$ nanowires (typically below $100 \mathrm{~nm}$ ) [13]. On the other hand, in some other studies of Si nanowire heterostructures, another extensively-studied diffusion source was metal nanowires or dots (refer to Table 1), which led to a point-contact rather than a planar contact to the Si nanowire $[8,9,37,38]$. Similarly, we have also studied the formation of $\mathrm{Ge}$ nanowire heterostructures through the point contact reaction between a $\mathrm{Ge}$ nanowire and a $\mathrm{Ni}$ nanowire. Figure 11(a) shows the TEM image of a Ge nanowire in point contact with two Ni nanowires on the TEM grid at room temperature. The Ni nanowires were prepared by the electrochemical deposition, and the diameter was typically $50-100 \mathrm{~nm}$ which depends on the size of the anodic aluminum oxide (AAO) template. Figure 11(b) shows the TEM image, similarly illustrating the diffusion 


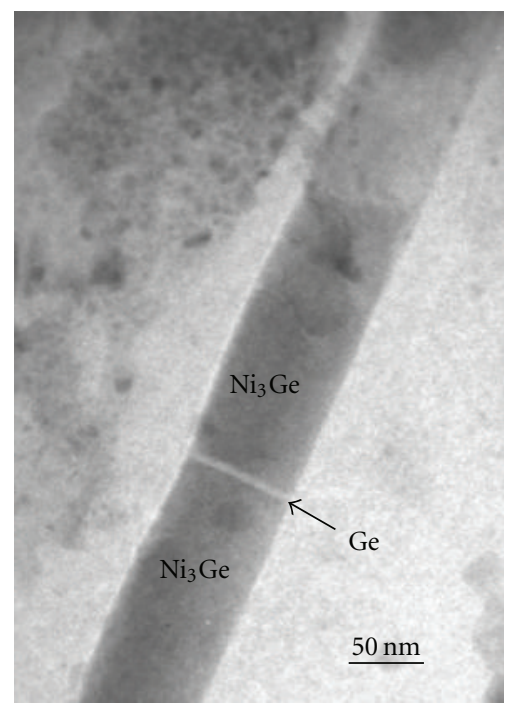

(a)

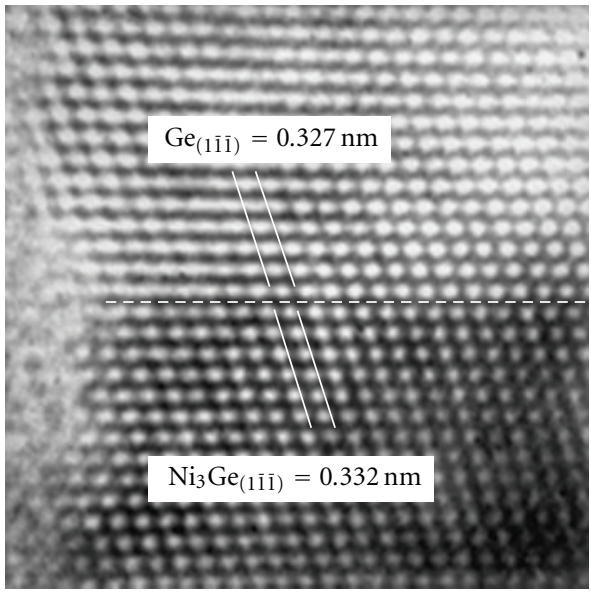

(c)

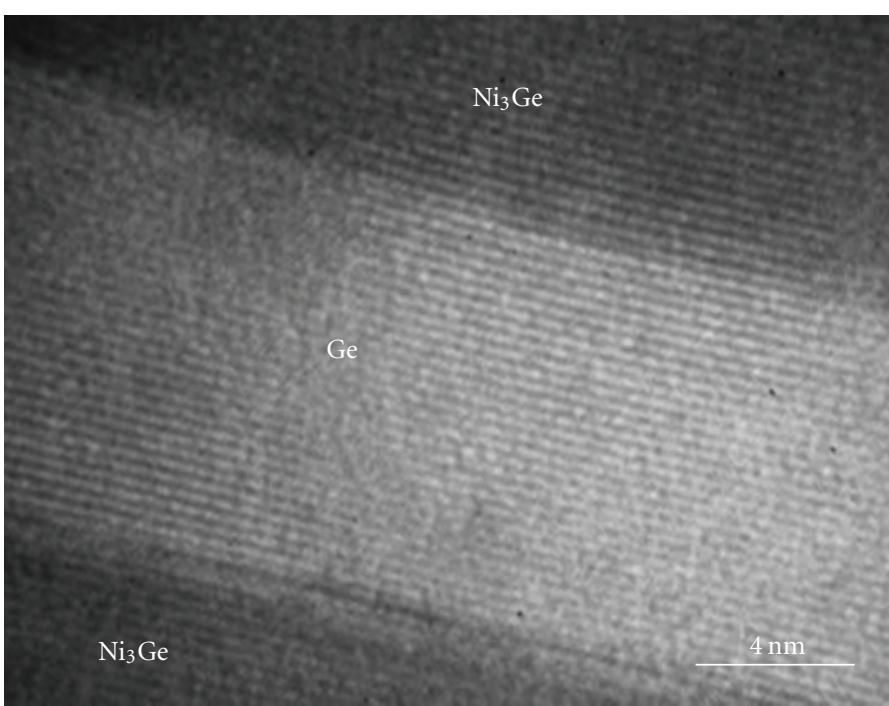

(b)

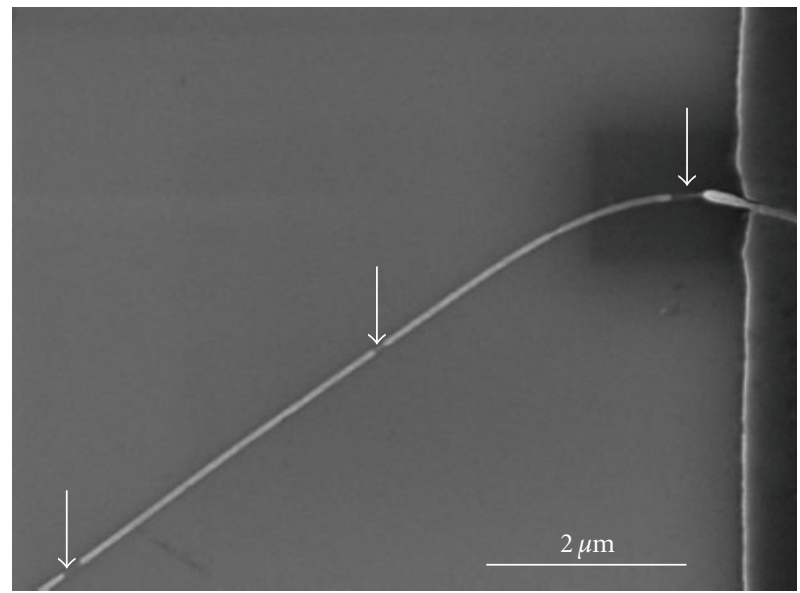

(d)

FIgure 12: (a) TEM image of a fragmented $\mathrm{Ni}_{3} \mathrm{Ge}$ nanowire on the TEM grid upon $650^{\circ} \mathrm{C}$ annealing. (b) HRTEM image of the $\mathrm{Ni}_{3} \mathrm{Ge} / \mathrm{Ge} / \mathrm{Ni}_{3} \mathrm{Ge}$ nanowire heterostructure showing a clean and sharp interface. (c) Lattice-resolved HRTEM image of the $\mathrm{Ni}_{3} \mathrm{Ge} / \mathrm{Ge}$ interface. The measured lattice mismatch was only $1.5 \%$ at the $\mathrm{Ni}_{3} \mathrm{Ge}(1 \overline{1} \overline{1}) / \mathrm{Ge}(1 \overline{1} \overline{1})$ interface. As a result, the twisted growth mode, which was observed in both $\mathrm{Ni}_{2} \mathrm{Ge} / \mathrm{Ge} / \mathrm{Ni}_{2} \mathrm{Ge}$ and $\mathrm{Ni}_{2} \mathrm{Ge} / \mathrm{NiGe} / \mathrm{Ge} / \mathrm{NiGe} / \mathrm{Ni}_{2} \mathrm{Ge}$ nanowire heterostructures to accommodate the large lattice mismatch, did not occur in this $\mathrm{Ni}_{3} \mathrm{Ge} / \mathrm{Ge} / \mathrm{Ni}_{3} \mathrm{Ge}$ nanowire heterostructure. (d) SEM image showing a broken Ge nanowire upon $650^{\circ} \mathrm{C}$ RTA due to a low melting pointing of the Ge nanowire. Reproduced from [13].

of $\mathrm{Ni}$ into the $\mathrm{Ge}$ nanowire upon $450^{\circ} \mathrm{C}$ annealing. The red arrows indicate the growth tip of the $\mathrm{Ni}_{x} \mathrm{Ge}$ nanowire. It is worth noting that the growth of the $\mathrm{Ni}_{x} \mathrm{Ge}$ nanowire started from the point-contact region, similar to the planar contact case [13]. However, this is different from the case of the $\mathrm{NiSi} / \mathrm{Si} / \mathrm{NiSi}$ nanowire heterostructure formed via the point-contact reaction between a $\mathrm{Si}$ nanowire and a $\mathrm{Ni}$ nanowire, in which the growth of NiSi actually started from both ends of the Si nanowire instead of the point-contact region [8]. Further kinetics study is needed to understand the different phenomena in Ge and Si nanowire heterostructures. Figure 11(c) TEM image of another Ge nanowire in point-contact with a $\mathrm{Ni}$ nanowire at room temperature. Figure 11(d) shows the TEM image illustrating the diffusion of $\mathrm{Ni}$ into the $\mathrm{Ge}$ nanowire upon $450^{\circ} \mathrm{C}$ annealing. Clear consumption of $\mathrm{Ni}$ in the formation of the $\mathrm{Ni}_{x} \mathrm{Ge}$ nanowire upon annealing was observed, as highlighted by the red circle. Moreover, it is surprising that the segregation of $\mathrm{Ni}_{x} \mathrm{Ge}$ nanoparticles was not observed in the Ni-Ge nanowire pointcontact system upon annealing [13]. We believe that the much smaller Ni flux through such point contact compared with the planar contact may play an important role in preventing the segregation of nanoparticles. Therefore, the difference of various metal contacts in the formation of Ge nanowire heterostructures requires further study.

For the device applications, we have demonstrated in this study that the formed germanides with atomically sharp interface to Ge can be used as a good electrical contact. 
Indeed, Lin et al. [11] have successfully detected the electrical spin injection into a $\mathrm{Si}$ nanowire from the ferromagnetic $\mathrm{MnSi}$ contact in the formed $\mathrm{MnSi} / \mathrm{Si} / \mathrm{MnSi}$ nanowire heterostructure. However, the signal can be observed only at relatively low temperature, since MnSi has a low Curie temperature of about $30 \mathrm{~K}$. On the other hand, there are many germanides, such as $\mathrm{Mn}_{5} \mathrm{Ge}_{3}$ and $\mathrm{Ni}_{3} \mathrm{Ge}$, which exhibit room-temperature ferromagnetism $[20,21]$, and thus offer great advantages over silicides for promising applications in room-temperature spintronics, including spin injection, transport and detection.

In fact, a room-temperature ferromagnetic germanide phase, $\mathrm{Ni}_{3} \mathrm{Ge}$ [20], was developed at high reaction temperature, in which a high-concentration $\mathrm{Ni}$ vapor from a large-area $\mathrm{Ni}$ contact pattern surrounded the Ge $\mathrm{NWs}$ to form a fragmented $\mathrm{Ni}_{3} \mathrm{Ge}$ nanowire. Figure 12(a) shows the TEM image of the formed $\mathrm{Ni}_{3} \mathrm{Ge} / \mathrm{Ge} / \mathrm{Ni}_{3} \mathrm{Ge}$ nanowire heterostructure on the TEM grid upon $650^{\circ} \mathrm{C}$ annealing. Figure 12(b) illustrates the HRTEM image of the $\mathrm{Ge}$ nanowire heterostructure with a clean and sharp interface between $\mathrm{Ni}_{3} \mathrm{Ge}$ and Ge. The $\mathrm{Ge}$ region was controlled down to as small as $12 \mathrm{~nm}$. The strained short $\mathrm{Ge}$ region in the $\mathrm{Ni}_{3} \mathrm{Ge} / \mathrm{Ge} / \mathrm{Ni}_{3} \mathrm{Ge}$ nanowire heterostructure is promising for high-performance FETs and spintronics applications [11,39]. Figure 12(c) shows the lattice-resolved TEM image of the $\mathrm{Ni}_{3} \mathrm{Ge}-\mathrm{Ge}$ interface, and the formed germanide was identified to be single-crystalline $\mathrm{Ni}_{3} \mathrm{Ge}$ with a face-centered cubic (FCC) lattice structure $(\mathrm{Fd} 3 \mathrm{~m}$, space group 227 and JCPDS no. 65-7680) and a lattice constant of $a=0.574 \mathrm{~nm}$. Although a slight volume expansion was still observed, the $\mathrm{Ni}_{3} \mathrm{Ge}$ lattice was well fit with the Ge lattice, due to their same lattice structure and a very small lattice mismatch of only $1.5 \%$ (the lattice constant of Ge is $a=0.568 \mathrm{~nm}$ ). It is worth mentioning that the twisted growth mode, which was observed in both $\mathrm{Ni}_{2} \mathrm{Ge} / \mathrm{Ge} / \mathrm{Ni}_{2} \mathrm{Ge}$ and $\mathrm{Ni}_{2} \mathrm{Ge} / \mathrm{NiGe} / \mathrm{Ge} / \mathrm{NiGe} / \mathrm{Ni}_{2} \mathrm{Ge}$ nanowire heterostructures to accommodate the large lattice mismatch, did not occur in this $\mathrm{Ni}_{3} \mathrm{Ge} / \mathrm{Ge} / \mathrm{Ni}_{3} \mathrm{Ge}$ nanowire heterostructure due to such a small lattice mismatch. However, as mentioned above, the melting point of Ge nanowires is significantly reduced from that of bulk Ge [29]. As a result, Ge nanowires were easily broken at high temperature, as shown in Figure 12(d). Therefore, a ferromagnetic germanide remains undeveloped at a relatively low temperature in order to study the spin transport in Ge nanowire.

\section{Acknowledgments}

This work was in part supported by Western Institution of Nanoelectronics (WIN) and Focus Center on Functional Engineered Nano Architectonics (FENA). The authors also acknowledged the support from National Science Council through Grant no. NSC 98-2221-E-007-104-MY3. J. Tang and C. Y. Wang contributed equally to the paper.

\section{References}

[1] D. Wang, Q. Wang, A. Javey et al., "Germanium nanowire field-effect transistors with $\mathrm{SiO}_{2}$ and high- $\kappa \mathrm{HfO}_{2}$ gate dielectrics," Applied Physics Letters, vol. 83, no. 12, pp. 24322434, 2003.

[2] M. I. Van Der Meulen, N. Petkov, M. A. Morris et al., "Single crystalline $\mathrm{Ge}_{1-x} \mathrm{Mn}_{x}$ nanowires as building blocks for nanoelectronics," Nano Letters, vol. 9, no. 1, pp. 50-56, 2009.

[3] Y. Huang, X. Duan, Y. Cui, L. J. Lauhon, K. H. Kim, and C. M. Lieber, "Logic gates and computation from assembled nanowire building blocks," Science, vol. 294, no. 5545, pp. 1313-1317, 2001.

[4] C. Thelander, H. A. Nilsson, L. E. Jensen, and L. Samuelson, "Nanowire single-electron memory," Nano Letters, vol. 5, no. 4, pp. 635-638, 2005.

[5] Y. Cui, Q. Wei, H. Park, and C. M. Lieber, "Nanowire nanosensors for highly sensitive and selective detection of biological and chemical species," Science, vol. 293, no. 5533, pp. 1289-1292, 2001.

[6] Y. Wu, J. Xiang, C. Yang, W. Lu, and C. M. Lieber, "Single-crystal metallic nanowires and metal/semiconductor nanowire heterostructures," Nature, vol. 430, no. 6995, pp. 61-65, 2004.

[7] W. M. Weber, L. Geelhaar, A. P. Graham et al., "Siliconnanowire transistors with intruded nickel-suicide contacts," Nano Letters, vol. 6, no. 12, pp. 2660-2666, 2006.

[8] K. C. Lu, W. W. Wu, H. W. Wu et al., "In situ control of atomicscale Si layer with huge strain in the nanoheterostructure $\mathrm{NiSi} / \mathrm{Si} / \mathrm{NiSi}$ through point contact reaction," Nano Letters, vol. 7, no. 8, pp. 2389-2394, 2007.

[9] Y. C. Chou, W. W. Wu, S. L. Cheng et al., "In-situ TEM Observation of repeating events of nucleation in epitaxial growth of nano $\mathrm{CoSi}_{2}$ in nanowires of Si," Nano Letters, vol. 8, no. 8, pp. 2194-2199, 2008.

[10] Y. C. Lin, K. C. Lu, W. W. Wu et al., "Single crystalline PtSi nanowires, $\mathrm{PtSi} / \mathrm{Si} / \mathrm{PtSi}$ nanowire heterostructures, and nanodevices," Nano Letters, vol. 8, no. 3, pp. 913-918, 2008.

[11] Y. C. Lin, Y. Chen, A. Shailos, and Y. Huang, "Detection of spin polarized carrier in silicon nanowire with single crystal $\mathrm{MnSi}$ as magnetic contacts," Nano Letters, vol. 10, no. 6, pp. 22812287, 2010.

[12] Y. Zhou, M. Ogawa, X. Han, and K. L. Wang, "Alleviation of Fermi-level pinning effect on metal/germanium interface by insertion of an ultrathin aluminum oxide," Applied Physics Letters, vol. 93, no. 20, Article ID 202105, 2008.

[13] J. Tang, C. Y. Wang, F. Xiu et al., "Single-crystalline $\mathrm{Ni}_{2} \mathrm{Ge} / \mathrm{Ge} / \mathrm{Ni}_{2} \mathrm{Ge}$ nanowire heterostructure transistors," Nanotechnology, vol. 21, no. 50, Article ID 505704, 2010.

[14] J. Tang, C. Y. Wang, F. Xiu et al., "Oxide-confined formation of Ge nanowire heterostructure for high-performance transistors," ACS Nano, vol. 5, no. 7, pp. 6008-6015, 2011.

[15] N. S. Dellas, S. Minassian, J. M. Redwing, and S. E. Mohney, "Formation of nickel germanide contacts to Ge nanowires," Applied Physics Letters, vol. 97, no. 26, Article ID 263116, 2010.

[16] T. Burchhart, A. Lugstein, Y. J. Hyun, G. Hochleitner, and E. Bertagnolli, "Atomic scale alignment of copper-germanide contacts for ge nanowire metal oxide field effect transistors," Nano Letters, vol. 9, no. 11, pp. 3739-3742, 2009.

[17] T. Burchhart, C. Zeiner, Y. J. Hyun, A. Lugstein, G. Hochleitner, and E. Bertagnolli, "High performance $\Omega$-gated Ge nanowire MOSFET with quasi-metallic source/drain contacts," Nanotechnology, vol. 21, no. 43, Article ID 435704, 2010.

[18] T. Burchhart, A. Lugstein, C. Zeiner, Y. J. Hyun, G. Hochleitner, and E. Bertagnolli, "Nanowire-metal heterostructures for 
high performance MOSFETs," Elektrotechnik und Informationstechnik, vol. 127, no. 6, pp. 171-175, 2010.

[19] K. Yamane, K. Hamaya, Y. Ando et al., "Effect of atomically controlled interfaces on Fermi-level pinning at metal/Ge interfaces," Applied Physics Letters, vol. 96, no. 16, Article ID 162104, 2010

[20] T. Izumi, M. Taniguchi, S. Kumai, and A. Sato, "Ferromagnetic properties of cyclically deformed $\mathrm{Fe}_{3} \mathrm{Ge}$ and $\mathrm{Ni}_{3} \mathrm{Ge}$," Philosophical Magazine, vol. 84, no. 36, pp. 3883-3895, 2004.

[21] M. Jamet, A. Barski, T. Devillers et al., "High-curie-temperature ferromagnetism in self-organized $\mathrm{Ge}_{1-x} \mathrm{Mn}_{x}$ nanocolumns," Nature Materials, vol. 5, no. 8, pp. 653-659, 2006.

[22] H. Y. Tuan and B. A. Korgel, "Importance of solvent-mediated phenylsilane decompositon kinetics for high-yield solutionphase silicon nanowire synthesis," Chemistry of Materials, vol. 20, no. 4, pp. 1239-1241, 2008.

[23] T. Hanrath and B. A. Korgel, "Supercritical fluid-liquid-solid (SFLS) synthesis of $\mathrm{Si}$ and Ge nanowires seeded by colloidal metal nanocrystals," Advanced Materials, vol. 15, no. 5, pp. 437-440, 2003.

[24] Y. L. Chueh, C. N. Boswell, C. W. Yuan et al., "Nanoscale structural engineering via phase segregation: Au-Ge system," Nano Letters, vol. 10, no. 2, pp. 393-397, 2010.

[25] A. D. Schricker, S. V. Joshi, T. Hanrath, S. K. Banerjee, and B. A. Korgel, "Temperature dependence of the field effect mobility of solution-grown germanium nanowires," Journal of Physical Chemistry B, vol. 110, no. 13, pp. 6816-6823, 2006.

[26] T. Hanrath and B. A. Korgel, "Influence of surface states on electron transport through intrinsic Ge nanowires," Journal of Physical Chemistry B, vol. 109, no. 12, pp. 5518-5524, 2005.

[27] S. Zhang, E. R. Hemesath, D. E. Perea, E. Wijaya, J. L. LenschFalk, and L. J. Lauhon, "Relative influence of surface states and bulk impurities on the electrical properties of Ge nanowires," Nano Letters, vol. 9, no. 9, pp. 3268-3274, 2009.

[28] Y. F. Hsieh, L. J. Chen, E. D. Marshall, and S. S. Lau, "Partial epitaxial growth of $\mathrm{Ni}_{2} \mathrm{Ge}$ and NiGe on Ge(1 11 1)," Thin Solid Films, vol. 162, pp. 287-294, 1988.

[29] Y. Wu and P. Yang, "Melting and welding semiconductor nanowires in nanotubes," Advanced Materials, vol. 13, no. 7, pp. 520-523, 2001.

[30] Y. C. Lin, Y. Chen, D. Xu, and Y. Huang, "Growth of nickel silicides in $\mathrm{Si}$ and $\mathrm{Si} / \mathrm{SiO}_{x}$ core/shell nanowires," Nano Letters, vol. 10, no. 11, pp. 4721-4726, 2010.

[31] Y. Zhou, W. Han, Y. Wang et al., "Investigating the origin of Fermi level pinning in Ge Schottky junctions using epitaxially grown ultrathin MgO films," Applied Physics Letters, vol. 96, no. 10, Article ID 102103, 2010.

[32] S. Ramo, J. R. Whinnery, and T. V. Duzer, Fields and Waves in Communication Electronics, John Wiley \& Sons, New York, NY, USA, 3rd edition, 1994.

[33] D. Wang, Y. L. Chang, Q. Wang et al., "Surface chemistry and electrical properties of germanium nanowires," Journal of the American Chemical Society, vol. 126, no. 37, pp. 11602-11611, 2004.

[34] Y. C. Chou, W. W. Wu, L. J. Chen, and K. N. Tu, "Homogeneous nucleation of epitaxial $\mathrm{CoSi}_{2}$ and $\mathrm{NiSi}$ in Si nanowires," Nano Letters, vol. 9, no. 6, pp. 2337-2342, 2009.

[35] L. J. Chen and W. W. Wu, "In situ TEM investigation of dynamical changes of nanostructures," Materials Science and Engineering R, vol. 70, no. 3-6, pp. 303-319, 2010.
[36] Y. C. Chou, W. W. Wu, C. Y. Lee, C. Y. Liu, L. J. Chen, and K. N. $\mathrm{Tu}$, "Heterogeneous and homogeneous nucleation of epitaxial $\mathrm{NiSi}_{2}$ in [ $\left.\begin{array}{lll}1 & 1 & 0\end{array}\right]$ Si nanowires," Journal of Physical Chemistry $C$, vol. 115, no. 2, pp. 397-401, 2011.

[37] K. C. Lu, K. N. Tu, W. W. Wu, L. J. Chen, B. Y. Yoo, and N. V. Myung, "Point contact reactions between $\mathrm{Ni}$ and $\mathrm{Si}$ nanowires and reactive epitaxial growth of axial nano-NiSi/Si," Applied Physics Letters, vol. 90, no. 25, Article ID 253111, 2007.

[38] W. W. Wu, K. C. Lu, C. W. Wang et al., "Growth of multiple metal/semiconductor nanoheterostructures through point and line contact reactions," Nano Letters, vol. 10, no. 10, pp. 3984-3989, 2010.

[39] W. W. Wu, K. C. Lu, K. N. Chen et al., "Controlled large strain of $\mathrm{Ni}$ silicide/Si/Ni silicide nanowire heterostructures and their electron transport properties," Applied Physics Letters, vol. 97, no. 20, Article ID 203110, 2010. 

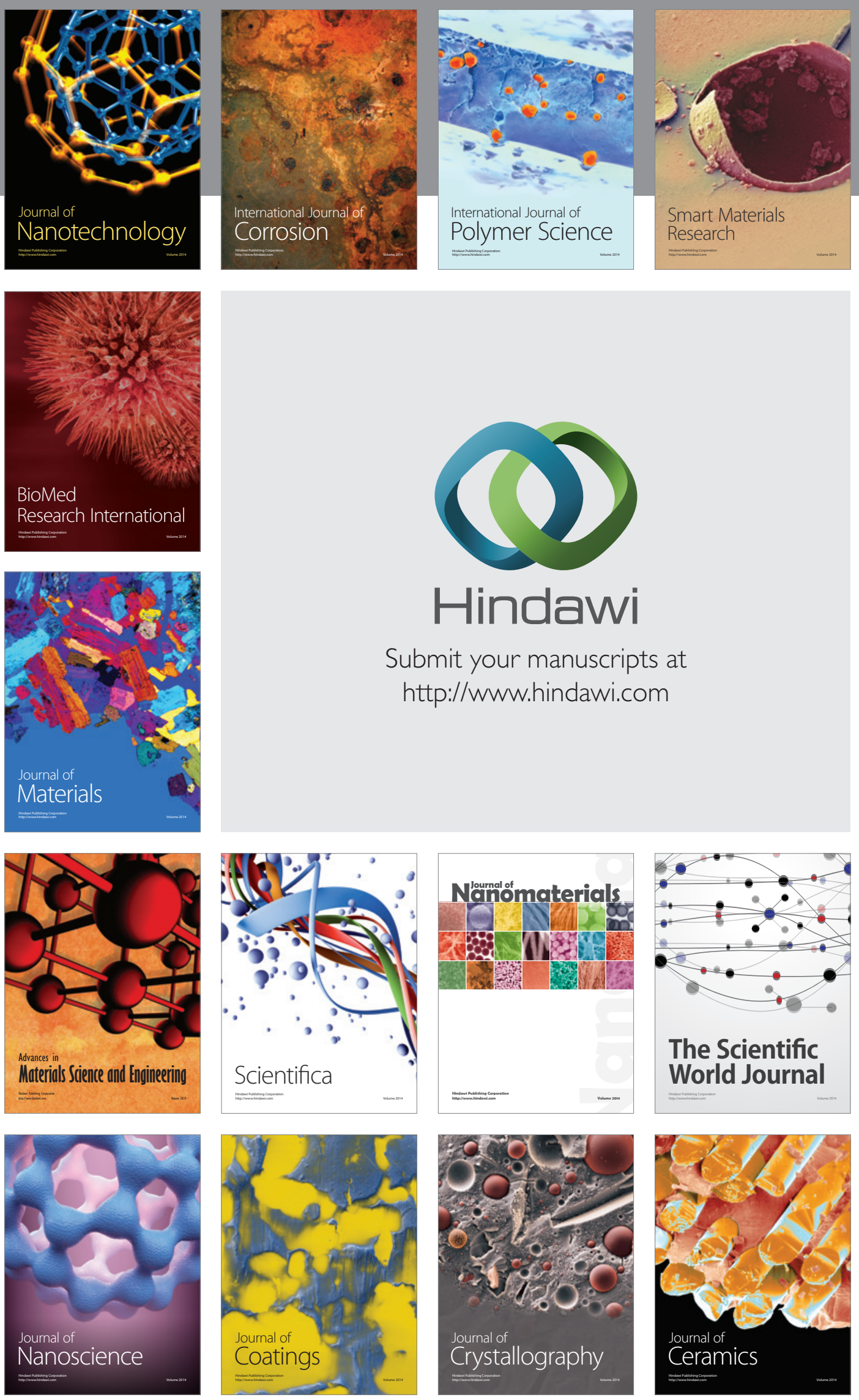

The Scientific World Journal

Submit your manuscripts at

http://www.hindawi.com

\section{World Journal}

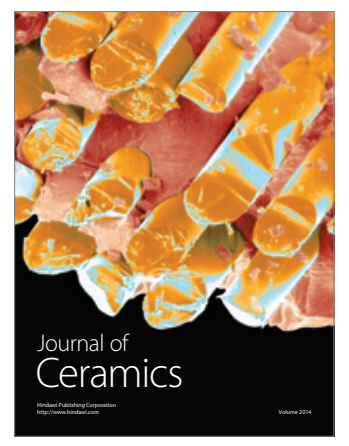

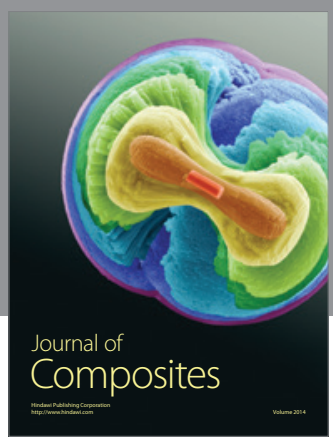
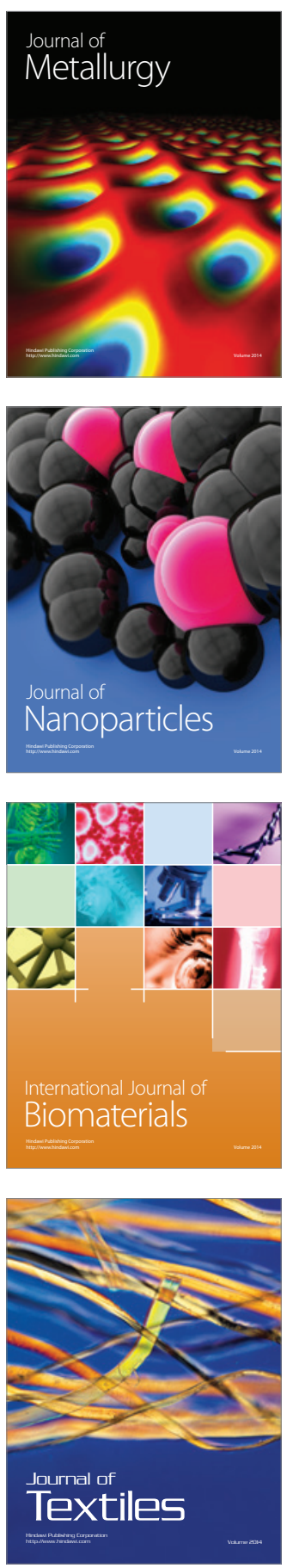